\title{
SOLANGE CARRASCO
}

\section{Aumento da expressão do receptor Toll-like $2 \mathrm{em}$ monócitos do sangue periférico de pacientes com artrite psoriásica.}

\begin{abstract}
Dissertação apresentada à Faculdade de Medicina da Universidade de São Paulo para obtenção do Título de Mestre em Ciências Médicas
\end{abstract}

Área de concentração:

Processos inflamatórios e alérgicos

Orientadora:

Dra. Cláudia Goldenstein-Schainberg

SÃO PAULO

2014 
A minha familia pela carinha, compreensãa e entusiasma.

A Regina, pela apaia e incentiva. fundamentais para a realizaçäa desta tese. Aos mens amigos, que faram meu cambustéuel no desenualuimenta deste trabalha. 


\section{AGRADECIMENTOS}

À Profa. Dra. Eloísa Silva Dutra de Oliveira Bonfá, pelo estímulo e oportunidade de ingressar na pós-graduação.

À Dra. Cláudia Godenstein-Schainberg, pela orientação, dedicação e paciência na realização deste trabalho.

À Dra. Suzana Beatriz Verissimo de Mello, pela motivação para o ingresso na pósgraduação.

Aos Drs. Célio Roberto Gonçalves, Percival Degrava Sampaio Barros e Carla Gonçalves Schahin Saad, pela grande ajuda no recrutamento dos pacientes no Ambulatório de Espondiloartrites.

Ao Dr. Fabrício de Souza Neves, que me auxiliou na parte clínica, por sua amizade e dedicação sempre.

Às Dras. Waldenise Cossermelli, Sandra Gofinet Pasoto e Bernadete de Lourdes Liphaus, pelas valorosas sugestões e esclarecimentos na confecção desta tese.

Ao Dr. Francisco Garcia Soriano, pela valiosa colaboração na discussão.

À Marcela Helena Gambim Fonseca, que me auxiliou nas coletas de sangue e no laboratório, por sua amizade e convivência.

Em especial a Tatiana Vasconcelos, Isabelle Camargo e Natasha Ugriumov, por todo o auxílio no dia-a-dia e pelos momentos de descontração.

Ao Dr. Edwin Roger Parra Cuentas e ao Dr. Hermes Barbeiro, pelo grande auxílio na estatística.

A Lia Negrão, pela competência e preciosa ajuda na formatação deste trabalho.

Aos meus amigos da Reumatologia, pela amizade e carinho no decorrer destes 19 anos de convivência.

Aos pacientes do Ambulatório de Espondiloartrites, pela inestimável colaboração, pois sem eles não seria possível a execução desta tese. 
Esta dissertação ou tese está de acordo com as seguintes normas, em vigor no momento desta publicação:

Referências: adaptado de International Committee of Medical Journals Editors (Vancouver).

Universidade de São Paulo. Faculdade de Medicina. Divisão de Biblioteca e Documentação. Guia de apresentação de dissertações, teses e monografias. Elaborado por Anneliese Carneiro da Cunha, Maria Julia de A. L. Freddi, Maria F. Crestana, Marinalva de Souza Aragão, Suely Campos Cardoso, Valéria Vilhena. 3a ed. São Paulo: Divisão de Biblioteca e Documentação; 2011.

Abreviaturas dos títulos dos periódicos de acordo com List of Journals Indexed in Index Medicus. 


\section{SUMÁRIO}

\section{Lista de Abreviaturas e Siglas}

Lista de Figuras

Lista de Tabelas

Resumo

\section{Abstract}

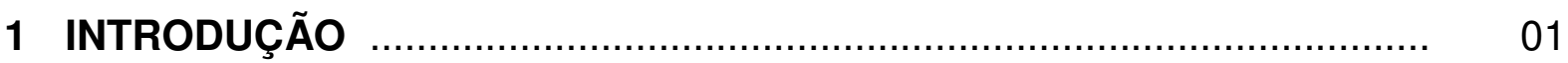

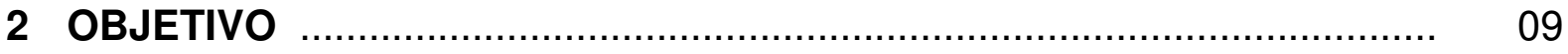

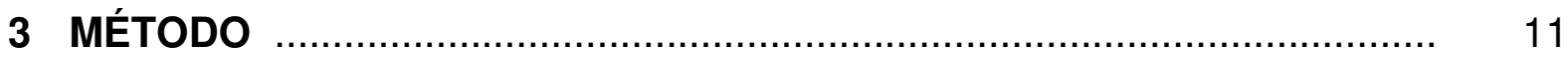

3.1 Casuística ........................................................................ 12

3.2 Obtenção do sangue periférico f............................................... 12

3.3 Marcação do sangue periférico com anticorpos monoclonais CD14 (monócitos), CD66 (neutrófilos), CD114 (G-CSF), CD116 (GM-CSF), TLR-2 e TLR-4

3.4 Avaliação quantitativa de monócitos e neutrófilos do sangue periférico.

3.5 Marcação do sangue periférico com anticorpo anti-HLA-B27 ligado à

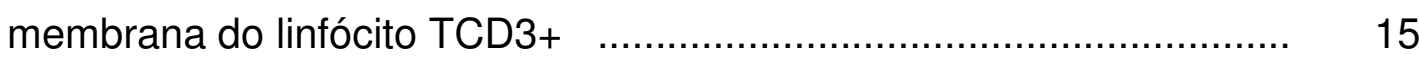

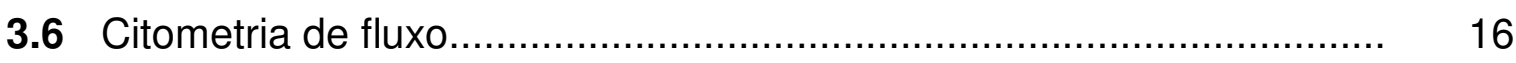

3.7 Análise estatística................................................................. 18

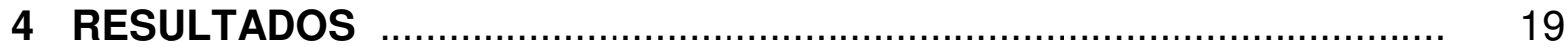

4.1 Características demográficas dos pacientes com APs....................... 20

4.2 Expressão dos receptores TLR-2 e TLR-4 ligados à membrana de monócitos e neutrófilos do sangue periférico com APS, APs ativa, APs inativa e controles

4.3 Expressão dos receptores CD114 e CD116 ligados à membrana de monócitos e neutrófilos do sangue periférico com APS, APs ativa, APs inativa e controles

4.4 Avaliação numérica de monócitos e neutrófilos do sangue de pacientes com APS, APs ativa, APs inativa e controles.

4.5 Expressão do antígeno HLA-B27 ligado à membrana de linfócito 
TCD3+

4.6 Expressão do TLR-2 em monócitos de pacientes com APs HLA-B27+ comparados aos controles HLA-B27+

5 DISCUSSÃO 29

6 CONCLUSÕES 35

7 ANEXOS 37

8 REFERÊNCIAS BIBLIOGRÁFICAS 40 Apêndice 


\section{LISTA DE ABREVIATURAS E SIGLAS}

AcMo

ACR

APs

AS

CASPAR

CAPPesq

CD

DAS 28

Dot-plot

EpA

EA

EDTA

ELISA

FACS

FCS

FcR
Anticorpos monoclonais

"American College Rheumatology"

Artrite Psoriásica

“Ankylosing Spondylitis” (Espondilite anquilosante)

Critério para o diagnóstico de artrite psoriásica

Comissão de Ética para Análise de Projetos de Pesquisa

"Cluster of differentiation" (grupamento de diferenciação)

“Disease activity score" (Escore de atividade da doença)

Gráfico de dispersão de pontos

“Espondiloartritis”

Espondilite Anquilosante

“Ethylenediamine tetra acetic acid” (Ácido etilenodiamino tetraacético)

Enzyme Linked Immuno Sorbent Assay

“Fluorescence-activated cell sorting” (Separação de células ativadas por fluorescência)

“Fetal calf serum" (Soro fetal bovino)

“Fc Receptor” (Receptor Fc) 
FSC

FITC

HCFMUSP

HLA

G-CSF

GM-CSF

LPS

LTA

$\mathrm{mL}$

$\mu \mathrm{L}$

PBS

PE

PerCP-Cy5.5
“Forward Scatter" (Fotodetector frontal do citômetro que evidencia o tamanho da célula)

"Fluorescein isothiocyanate" (Isotiocianato de fluoresceína - cor verde)

Hospital das Clínicas da Faculdade de Medicina da Universidade de São Paulo

“Human Leukocyte Antigen” (Antígeno leucocitário humano ou antígeno de histocompatibilidade)

Granulocyte colony-stimulating fator (Fatores solúveis estimuladores de colônias de granulócitos)

Granulocyte-macrophage colony-stimulating fator (Fatores estimuladores de colônias de granulócitos-macrófagos)

Lipopolissacarídeo

“Lipoteichoic acid” (Ácido lipoteicóico)

Mililitro

Microlitro

"Phosphate buffered saline" (Solução salina em tampão fosfato)

"Phycoerythrin" (Ficoeritrina - cor laranja)

"Peridin-chlorophyll proteins complex" (Complexo proteína peridina-clorofila) 
PMN

PPRs

PsO

RA

rpm

SpA

SSC

TCLE

TLR

TNF- $\alpha$
Polimorfonucleares

Pattern recognition receptors (Receptores de reconhecimento padrão)

Psoríase

"Rheumatoid arthritis" (Artrite reumatoide)

Rotação por minuto

"Spondyloarthritis" (Espondiloartrite)

"Side scatter" (fotodetector lateral do citômetro, que evidencia a complexidade ou granulidade da célula)

Termo de consentimento livre e eslarecido

“Toll-like receptor” (Receptor toll-like)

“Tumor necrosis factor alpha” (Fator de necrose tumoral alfa) 


\section{LISTA DE FIGURAS}

Figura 1 - Figura representativa das marcações por citometria de fluxo.

Figura 2 - Gráfico da análise por citometria de fluxo dos monócitos e neutrófilos marcados com TLR-2 e TLR-4 de um paciente com artrite psoriásica.

Figura 3 - Gráfico da análise por citometria de fluxo dos monócitos e neutrófilos marcados com TLR-2 e TLR-4 de um controle.

Figura 4 - Gráfico da análise por citometria de fluxo do marcador genético HLA-B27 em um paciente com artrite psoriásica e controle. 


\section{LISTA DE TABELAS}

Tabela 1 - Expressão do TLR-2 em monócitos e neutrófilos do sangue periférico de pacientes com APs, APs ativa, APs inativa e controles.

Tabela 2 - Expressão do TLR-4 em monócitos e neutrófilos do sangue periférico de pacientes com APs, APs ativa, APs inativa e controles.

Tabela 3 - Expressão do CD114 em monócitos e neutrófilos de pacientes com APs, APs ativa, APs inativa e controles.

Tabela 4 - Expressão do CD116 em monócitos e neutrófilos de pacientes com APs, APs ativa, APs inativa e controles.

Tabela 5 - Comparação quantitativa do número de monócitos e neutrófilos do sangue periférico, por citometria de fluxo, de pacientes com APs, APs ativa, APs inativa e controles. 


\section{RESUMO}

CARRASCO, S. Aumento da expressão do receptor Toll-like 2 em monócitos do sangue periférico de pacientes com artrite psoriásica [Dissertação]. São Paulo: Faculdade de Medicina. Universidade de São Paulo: 2014.

INTRODUÇÃO: Os receptores Toll-like 2 e 4 (TLR-2 e TLR-4) são capazes de ativar células imunes inatas em resposta a bactérias Gram-positivas e Gram-negativas, respectivamente. $\mathrm{Na}$ artrite psoriásica (APs), doença articular inflamatória crônica, fatores genéticos, ambientais e infecciosos parecem estar envolvidos. OBJETIVO: Avaliar as expressões dos receptores: TLR-2; TLR-4; CD114 e do CD116 em monócitos e neutrófilos do sangue periférico de pacientes com APs e adicionalmente a prevalência do HLA-B27. MÉTODOS: Quarenta e cinco pacientes com diagnóstico de APs conforme os critérios CASPAR e 32 indivíduos saudáveis foram estudados. Dentre os 45 pacientes, 27 apresentavam APs ativa (DAS28 $\geq 2,6$ ) e 18 APs inativa (DAS28 < 2,5). A leitura das expressões do TLR-2, TLR-4, CD14, CD66, CD114, CD116 e do HLA-B27 foi realizada por citometria de fluxo no FACSCalibur da marca Becton-Dickson, utilizando anticorpos monoclonais da BD Biosciences, anti-humanos produzidos em murino. Os anticorpos monoclonais (AcMo) para marcar receptores de membrana empregados foram: CD14 conjugado com PerCP-Cy5.5 para marcar população de monócitos; CD66 conjugado com PE e FITC para população de neutrófilos; CD114 para marcar receptor de fator estimulatório de colônias de granulócitos e CD116 para marcar receptor de fator estimulatório de colônia de granulócitos-macrófagos. A análise estatística utilizou o teste $U$ de Mann-Whitney e o teste exato de Fisher. Os valores obtidos em porcentagem foram expressos como média \pm intervalo interquartil, de acordo com uma distribuição não-paramétrica, avaliados pelo teste de Shapiro-Wilk. RESULTADOS: Demonstramos aumento de expressão do TLR-2 em monócitos periféricos de pacientes com APs, APs ativa e APs inativa comparados aos controles ( $p<0,002 ; p<0,001$ e $p<0,04$, respectivamente). A expressão do TLR-4 foi similar nos pacientes com APs, APs ativa e APs inativa e controles ( $p<0,23 ; p<0,33$ e $p<0,29$, respectivamente). A expressão do receptor $G$ CSF (CD114) e do receptor GM-CSF (CD116) foi similar nos pacientes e controles nas populações de monócitos e neutrófilos ( $p>0,05$ ). O HLA-B27 foi positivo em 1/3 dos pacientes com APs e $6 \%$ dos controles. Nos pacientes HLA-B27+ comparados aos controles HLA-B27+, a porcentagem de expressão do TLR-2 nos monócitos foi significantemente maior $(p<0,004)$. CONCLUSÃO: O aumento da expressão do TLR-2 em monócitos de pacientes com APs reforça o papel da imunidade inata e sugere que a exposição a bactérias Gram-positivas possa ter um papel na indução da resposta inflamatória nesta doença.

\section{Palavras-chave}

Artrite psoriásica, receptores Toll-like, imunidade inata, monócitos e neutrófilos, HLAB27 


\section{ABSTRACT}

CARRASCO, S. Increased expression of Toll-like receptor 2 in peripheral blood monocytes from patients with psoriatic arthritis [Dissertation]. São Paulo: Faculdade de Medicina. Universidade de São Paulo: 2014.

INTRODUCTION: Toll-Like receptors 2 and 4 (TLR-2 and TLR-4) are able of activating innate immune cells in response to Gram-positive and Gram-negative bacteria, respectively. In Psoriatic Arthritis (APs), chronic inflammatory joint disease and genetic, environmental and infectious factors seems to be involved. OBJECTIVES: Evaluate expressions of TLR-2; TLR-4; CD114 and CD116 receptors in monocytes and neutrophils from peripheral blood patients with APs and additionally the prevalence of HLA-B27. METHODS: Forty five patients diagnosed with APs according with CASPAR criteria and 32 health individuals were studied. Among the 45 patients, 27 presented active APs (DAS28 $\geq 2,6$ ) and 18 inactive APs (DAS28 <2,5). The evaluation of the TRL-2, TLR-4, CD14, CD66, CD114, CD116 and HLA-B27 expressions was held by flow cytometry in FACSCalibur from Becton-Dickson, utilizing BD Biosciences' monoclonal antibodies, anti-human produced in mice. The monoclonal antibodies (AcMo) used to mark membrane receptors were: CD14 in conjunction with PerCP-Cy 5.5 to mark population of monocytes; CD66 in conjunction with PE and FITC for population of neutrophils; CD114 to mark stimulatory factor receptor for granulocyte colonies and CD116 to mark stimulatory factor receptor for granulocyte-macrophage colony. The statistical analysis utilized Mann-Whitney's U test and Fisher's exact test. The values obtained as percentages were expressed as median \pm interquartile range, consistent with a non-parametrical distribution, assessed by Shapiro-Wilk's test. RESULTS: Increased expression of TLR-2 in peripheral monocytes of patients with APs, active APs and inactive APs compared to controls $(p<0.002 ; p<0.001$ and $p<0.04$, respectively). TLR-4 expression was similar in patients with APs, active APs and inactive APs and controls $(p<0.23 ; p<0.33$ and $p<.029$ respectively). The expression of the G-CSF (CCD114) receptor and GM-CSF (CD116) receptor were similar in patients and controls in populations of monocytes and neutrophils ( $p>0.05$ ). HLA-B27 was positive in $1 / 3$ of the patients with APs and $6 \%$ of the controls. The percentage of expression of TLR-2 in HLA-B27 + patients compared to HLA-B27 + controls was significantly higher $(p<0.004)$. CONCLUSION: Increased of TLR-2 receptors expression in patients with APs monocytes reinforces the role of innate immunity and suggests that the exposure to Gram-positive bacteria may have a role in the induction of the inflammatory response in this disease.

\section{Keywords}

Psoriatic arthritis, toll-like receptors, innate immunity, neutrophils, monocytes, HLAB27 
INTRODUÇÃO 


\section{Introdução}

A artrite psoriásica (APs) é uma doença inflamatória crônica das articulações associada à psoríase cutânea, que pode acometer o esqueleto axial, com sacroilíte, além das articulações periféricas [1]. Louis Aliberti (1818), citado por Gladman (2009) [2], descreveu pela primeira vez a doença e, atualmente, estima-se que a sua prevalência na população mundial seja de 0,02\%-0,025\% [3]. A APs ocorre em ambos os sexos e em todas as faixas etárias [4], apesar de sua incidência ser maior dos 40 a 50 anos de idade [5]. A prevalência da psoríase cutânea isolada na população é de $2 \%$ a $3 \%$ e sua associação com artrite ocorre em $6 \%$ a $42 \%$ dos pacientes $[1,6]$. $O$ envolvimento da pele precede a artrite em aproximadamente $75 \%$ dos casos, em $10 \%$ o quadro cutâneo e o articular são simultâneos e em 15\% o comprometimento cutâneo é posterior [7]. De fato, as lesões eritemato-descamativas na pele podem preceder em meses ou anos a inflamação nas articulações, estruturas músculoesqueléticas e partes moles adjacentes, com sintomas de dor, edema e rigidez, particularmente nos dedos das mãos e dos pés, sendo que o desencadeamento da APs pode ocorrer após estresse emocional [8, 9]. Em 1973, Moll e Wright propuseram a classificação da APs em 5 subgrupos ou formas clínicas distintas: a forma distal clássica, a oligoarticular assimétrica, a poliarticular semelhante à artrite reumatóide, a espondilitica e a mutilante [1]. No entanto, estudos posteriores mostraram superposição destas formas em boa parte dos pacientes, de modo que a tendência atual é classificar a APs em: poliarticular (41\%), oligoarticular (31\%), axial e periférica (28\%) [10]. É importante ressaltar que o fator reumatoide sérico é ausente em todos os subgrupos [1]. O diagnóstico de APs é baseado nos critérios CASPAR (Anexo A), no qual é necessária a presença de doença inflamatória articular, seja ela periférica, 
axial ou entesítica, e atingir pelo menos 3 pontos dentre 5 categorias: evidência de psoríase; distrofia ungueal psoriásica; fator reumatóide negativo; dactilite atual ou prévia; e evidência radiológica de neoformação óssea justa-articular [10].

A etiopatogenia da APs permanece desconhecida, mas acredita-se haver influência de fatores ambientais, infecciosos e imunogenéticos [9, 11].

O traço genético PSORS1-9 associado à APs favoreceu o conceito da base genética multifatorial, que se intensificou com a descoberta de mais de 20 loci candidatos associados à suscetibilidade para a expressão da doença $[12,13,14]$. De fato, vários loci de suscetibilidade envolvidos na APs tem sido implicados, principalmente os alelos do antígeno leucocitário humano (HLA - Human Leukocyte Antigen) de classe I, indicando ser uma doença geneticamente heterogênea [12]. O alelo HLA-Cw6 foi o mais associado, apesar de presente em $40 \%$ a $80 \%$ dos casos, mas também em $10 \%$ a $15 \%$ dos controles [13]. Pacientes HLA-Cw0602+ iniciam a psoríase em idade mais jovem e têm doença de pele mais extensa e grave, enquanto que alterações ungueais e artrite são mais comuns nos pacientes HLA-Cw6- [12]. Polimorfismos nos genes codificados na região do cromossomo $6 p$ igualmente foram associados à APs $[15,16]$. Outros marcadores como HLA-B13, HLA-B57, HLA-B39 e HLA-Cw7 também parecem ter associação positiva em estudos populacionais de psoríase e APs, embora mais forte com o HLA-Cw629 [17]. Alguns alelos parecem identificar um determinado padrão de APs, como o HLA-B27 com envolvimento axial, HLA-DR4 com forma erosiva e os HLA-DR7, HLA-B38 e HLA-B39 com poliartrite periférica [15]. Outros foram identificados como fator prognóstico, isto é, HLA-B39 isolado, HLA-B27 na presença de HLA-DR7 ou HLA-DQw3 na ausência de HLA-DR7, parecem conferir maior gravidade aos pacientes com APs, enquanto que o HLA-B22 
parece ser protetor para progressão da doença [18]. Em relação ao HLA-B27, conforme a literatura mundial e de acordo com a região geográfica, pode estar presente em $20 \%$ a $60 \%$ dos doentes com APs [15,16], com maior incidência nas formas axiais ou espondilíticas [1,2]. Em nosso meio, 2 trabalhos analisaram a frequência do HLA-B27 em 22 e 102 pacientes brasileiros com APs [19,20]. No estudo de Belo Horizonte [19] o HLA-B27 foi positivo em 36\% (8/22) pelo método de microlinfotoxidade, enquanto que no grupo de Campinas [20] sua positividade por PCR (polimerase chain reaction) foi de $21 \%$ (21/102), sobretudo nos espondilíticos.

Observações clínicas e laboratoriais sugerem o papel de agentes infecciosos na etiopatogenia da APs. Neste sentido, Vasey e colaboradores (1982) e Rantakokko e colaboradores (1997) encontraram, nos soros de pacientes com APs e psoríase, títulos elevados de anticorpos contra diferentes componentes da parede celular de estreptococos, incluindo peptidoglicanos e peptidoglicanos polissacárides, quando comparados àqueles com artrite reumatoide e controles saudáveis [21,22]. Esta resposta humoral específica notada sugere que bactérias da flora cutânea possam ser importantes no desencadeamento e/ou perpetuação da doença [21, 22].

Várias células, como fagócitos, incluindo neutrófilos e macrófagos, além de monócitos e células dendríticas, participam do reconhecimento de patógenos estimulando a resposta imunológica [23]. A imunidade inata é a primeira linha de defesa do organismo contra substâncias estranhas e infecciosas, como bactérias, por meio de barreiras físicas e químicas [23]. A ativação das células da imunidade inata ocorre por meio do reconhecimento de antígenos bacterianos via receptores Toll-like (TLRs) [24]. Os TLRs são glicoproteínas tipo I integrais de membrana; possuem um domínio homólogo ao receptor de IL-1 em sua cauda citoplasmática e um domínio 
externo rico em leucina e cisteína, onde estão os receptores de reconhecimento padrão altamente conservados, os PRRs (pattern recognition receptors), responsáveis pelo desencadeamento da resposta imune. Dez TLRs foram descritos em humanos e 13 em camundongos [25]. Os TLRs reconhecem padrões moleculares associados a patógenos (PAMPs) e padrões moleculares associados a danos (DAMPs), sendo capazes de iniciar e perpetuar a resposta inflamatória. Os PAMPs abrangem diversos ligantes, como lipoproteína, lipopolissacáride (LPS), flagelinas e ácidos nucleicos de bactérias, vírus e parasitas, e os DAMPs incluem moléculas endógenas originadas de danos teciduais [26]. A ativação dos múltiplos TLRs gera a liberação das citocinas pró-inflamatórias, tais como IL-1, IL-6, TNF- $\alpha$ e IFN- $\beta$. Em indivíduos com predisposição genética, esta ativação desregulada pode levar à quebra da tolerância imunológica periférica e por sua vez o desenvolvimento de doenças autoimunes, como lúpus eritematoso sistêmico, artrite reumatóide, esclerodermia sistêmica e APs $[27,28]$.

O TLR-2 é capaz de reconhecer vários padrões moleculares, como os peptidoglicanos, que são os principais constituintes da parede bacteriana de organismos Gram-positivos, enquanto que o TLR-4 reconhece os LPS, componentes básicos da parede das bactérias Gram-negativas [29, 30].

A molécula CD14 é um receptor importante no reconhecimento de ligantes microbianos, altamente expressa em monócitos circulantes, mas também em neutrófilos. Na membrana dos neutrófilos, a expressão do TLR-2 e do CD14 é regulada por fatores solúveis estimuladores de colônias de granulócitos (G-CSFGranulocyte colony-stimulating factor - receptor CD114) e por fatores estimuladores de colônias de granulócitos-macrófagos (GM-CSF- Granulocyte-macrophage colony- 
stimulating factor - receptor CD116) [31]. O G-CSF é gerado em locais de infecção e atua como um hormônio endócrino capaz de mobilizar os neutrófilos da medula e repô-los, caso sejam consumidos na reação inflamatória; também funciona como coreceptor juntamente com o TLR-4 para ligação ao LPS bacteriano. Por outro lado, o GM-CSF promove a maturação de células da medula óssea, originando células dendríticas e monócitos [23]; sensibilizam estas células a responderem de forma exacerbada à estimulação subsequente com agonistas do TLR-2 [31]. É importante ressaltar que ambos - o TLR-2 e o TLR-4 - ativam monócitos e neutrófilos a produzirem citocinas pró-inflamatórias envolvidas em doenças inflamatórias crônicas $[28,30]$.

$\mathrm{Na}$ psoríase, há maior proliferação de queratinócitos, infiltrado de células inflamatórias e angiogênese aumentada, que podem anteceder a ocorrência da manifestação articular, ou seja, da APs [32]. A nível tecidual, e por imunohistoquímica, demonstrou-se aumento de expressão do TLR-2 na epiderme; na derme, células dendríticas expressaram TLR-2 e TLR-4, mas não TLR-9, enquanto que células dendríticas da epiderme expressaram TLR-4, mas não TLR-2 nem TLR-9 (32). Já nas células mononucleares do sangue periférico, Garcia-Rodriguez e colaboradores (2011) demonstraram aumento importante da expressão gênica do TLR-4 e aumento moderado da expressão gênica do TLR-2, enfatizando o envolvimento da resposta imune inata nesta doença [33]. Begon E. e colaboradores (2007) [34] haviam estudado a expressão de TLRs 1, 2, 3, 4, 5 e 6 em pacientes com psoríase e observaram que apenas a expressão do TLR-2 estava aumentada em lesões cutâneas e em células obtidas de cultura de queratinócitos estimulados com peptidoglicanos e LPS [30]. Alguns autores argumentam que os queratinócitos 
possam ser a chave do processo inflamatório que, após estímulo, liberam citocinas pró-inflamatórias [35], como TNF- $\alpha$ e IL-8 [30], promovendo o recrutamento de células $\mathrm{T}$ [35]. Assim, na psoríase, um estímulo infeccioso ou ambiental poderia atuar como gatilho, interferindo na imunidade inata, levando à ativação de queratinócitos e sinoviócitos [32] com liberação de IL-1 e TNF- $\alpha$ ativando as células dendríticas da epiderme e da derme [32]. Estas células ativadas processam o antígeno e migram para os linfonodos, promovendo o recrutamento de células inflamatórias como células T e B para o tecido lesado. Assim, os linfócitos T ativados de doentes psoríasicos se diferenciariam preferencialmente em células TCD4+ tipo 1 (Th1; produtores de INF-ץ , TNF- $\alpha$ e IL-2), tipo 17 (Th17; produtores de IL-17, TNF- $\alpha$, IL-6 e IL-22) e TCD8+ tipo 1 (Tc1; produtores de TNF- $\alpha$, INF-ץ, perforinas e granzima B) [36]. Portanto, estas citocinas pró-inflamatórias juntamente com o aumento da angiogênese auxiliariam o recrutamento dos linfócitos, perpetuando o processo inflamatório.

Em pacientes com APs, apenas um estudo analisou o possível papel etiopatogênico dos TLRs. Candia e colaboradores (37) avaliaram a expressão do TLR-2 e do TLR-4 em monócitos do sangue periférico de 10 indivíduos com APs ativa, artrite reumatoide e controles por citometria de fluxo e Western Blot. Os monócitos foram estimulados in vitro com GM-CSF concomitante com IL-4 e LPS, no intuito de promover sua diferenciação em células dendríticas imaturas e em células dendríticas maduras, respectivamente. Os autores observaram expressão aumentada do TLR-2 nas células dendríticas imaturas de pacientes com doença ativa, mas não naqueles com artrite reumatoide e controles normais. No sobrenadante de cultura de monócitos notaram aumento de produção de TNF-a e IFN- $\gamma$, sugerindo um padrão Th1 de resposta, mas não de IL-2, IL-4, IL-5, IL-10 nem IL-12 [37]. 
Portanto, parece que, na psoríase e na APs, o aumento da expressão do TLR-2, aliado à maior produção de citocinas pró-inflamatórias, sugere o papel da imunidade inata na patogênese da doença psoriásica, onde bactérias Gram-positivas poderiam atuar como gatilho para o seu desenvolvimento. Entretanto e diante da escassez de estudos consistentes que esclareçam a participação da imunidade inata na APs, conduzimos este estudo. Desta forma, no intuito de investigar esta hipótese, avaliamos a expressão do TLR-2 e do TLR-4 em monócitos e neutrófilos do sangue periférico de um maior número de pacientes com APs, comparando doentes com doença ativa e inativa. Adicionalmente, verificamos as expressões dos receptores de G-CSF (CD114) e GM-CSF (CD116) e a prevalência do antígeno HLA-B27 em amostra de pacientes brasileiros com APs pertencentes a um único centro. 
OBJETIVOS 


\section{Objetivos}

> Estudar em monócitos e em neutrófilos do sangue periférico de pacientes com APs, e considerando a influência da atividade clínica da doença, a expressão dos receptores:

- TLR-2 e TLR-4.

- G-CSF (CD114) e GM-CSF (CD116).

Determinar a prevalência do antígeno HLA-B27 em uma grande amostra de pacientes brasileiros com APs pertencentes a um único centro. 
MÉTODOS 


\section{Métodos}

\subsection{Casuística}

Durante o período de 24 meses, pacientes consecutivos com diagnóstico definido de APs acompanhados no ambulatório de espondiloartrites (EpA) da Disciplina de Reumatologia do Hospital das Clínicas da Faculdade de Medicina da Universidade de São Paulo (HCFMUSP) foram estudados. Todos os sujeitos preencheram os critérios CASPAR (Anexo A) [10]. Foram incluídos pacientes com doença periférica e excluídos aqueles com doença axial isolada e/ou com intercorrências infecciosas. O grupo controle foi formado por voluntários saudáveis do Laboratório de Investigação Médica em Reumatologia (LIM-17) do HCFMUSP. Este estudo baseou-se nos princípios da Declaração de Helsinki, recebendo aprovação do Comitê de Ética institucional (CAPPesq nº 0533/07) e todos os indivíduos assinaram o termo de consentimento livre e esclarecido (Apêndice) antes do início do estudo.

Como o quadro clínico era sobretudo periférico, o escore de atividade de doença DAS28 (Anexo B) foi utilizado para avaliar a atividade clínica da APs. Este se baseia na contagem de 28 articulações dolorosas e edemaciadas, na velocidade de hemossedimentação (VHS) e na avaliação global de saúde (AGS), e considera pacientes com doença clinicamente ativa aqueles com DAS $28 \geq 2,6$ [40].

\subsection{Obtenção de sangue periférico}

Amostras de $5 \mathrm{~mL}$ de sangue foram coletados de todos pacientes com APs e controles por punção venosa periférica em tubos com EDTA, para posterior marcação com anticorpos monoclonais apropriados. 


\subsection{Marcação do sangue periférico com anticorpos monoclonais}

Após coleta do sangue periférico, $200 \mu \mathrm{L}$ de sangue de pacientes com APs e controles foram colocados em cada 1 dos 6 tubos contendo $2 \mathrm{~mL}$ de tampão fosfato salina com azida $0,1 \%$ phosphate buffered saline (PBS); em seguida à centrifugação a 2.000 rpm por 3 minutos, $50 \mu \mathrm{L}$ de PBS-azida $0,1 \%$ com soro fetal bovino $2 \%$ (SFB) foram adicionados. Quatro dos 6 tubos foram centrifugados e incubados durante 20 minutos com o receptor $\mathrm{Fc}$ anti-humano não-conjugado (reagente de bloqueio $\mathrm{FcR}$, eBioscience, San Diego, CA, EUA) para evitar a subsequente aderência nãoespecífica de anticorpos monoclonais (AcMo).

Seguindo as instruções do fabricante (BD Biosciences, San Jose, CA, EUA), as células do sangue periférico distribuídas nos 6 tubos foram coradas por 20 minutos com os seguintes anticorpos monoclonais anti-humanos produzidos em murinos: a) anti-CD66 conjugado com ficoeritrina (PE - amarelo) e com isotiocianato de fluoresceína (FITC - verde) para marcação específica de neutrófilos; b) anti-CD14 conjugado com complexo proteína peridinina-clorofila (PerCP-Cy5. 5 - vermelho forte) para marcação de monócitos; c) anti-TLR-2 conjugado com Alexa-fluor®; d) anti-TLR4 biotinilado conjugado com estreptavidina marcada com isotiocianato de fluoresceína -FITC; e) anti-CD114 conjugado com PE para marcação de receptor G-CSF (fator estimulatório de colônias de granulócitos); f) anti-CD116 conjugado com FITC como marcador de receptor GM-CSF (fatores estimulatórios de colônias de granulócitosmacrófagos). 
As compensações do citômetro de fluxo antes de cada análise foram realizadas utilizando marcação com anticorpos isotípicos para cada fluorocromo (FL1, FL-2 e FL-3) como controle negativo. Para o controle positivo, as células sanguíneas foram marcadas em um único tubo com anti-TCD3 (PerCP) FL-3, antiTCD4 (PE) FL-2 e anti-TCD8 (FITC) FL-1 (Figura 1).
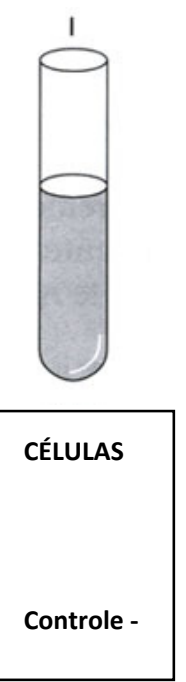
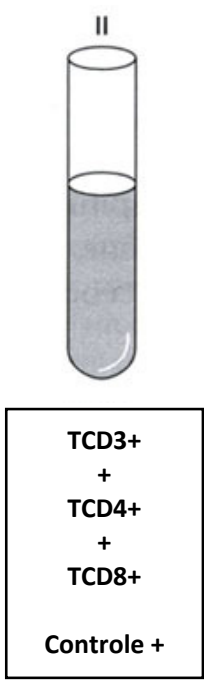
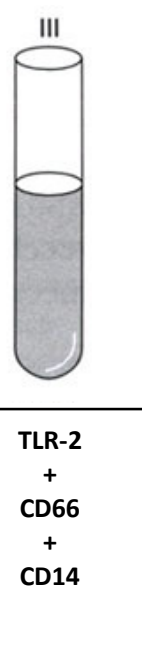
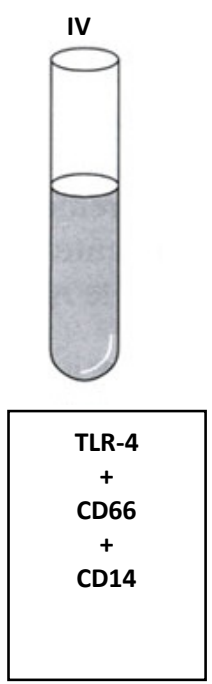
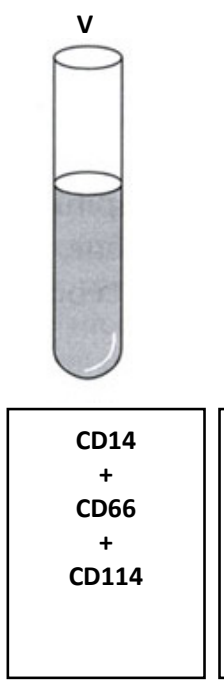
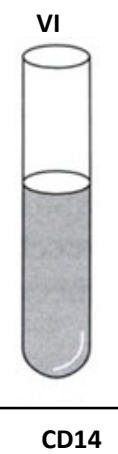

$+$ CD66 $+$ CD116

Figura 1. Figura representativa das marcações de citometria de fluxo.

TLR-2 e TLR-4 = Toll like-receptors, CD66 = neutrófilos, CD14= monócitos CD116 = GM-CSF (Fatores estimulatórios de colônias de granulócitos-macrófagos) CD114 = G-CSF (Fator estimulatório de colônias de granulócitos), TCD3 = Linfócitos

Após marcação com os monoclonais e para melhor visualização das células brancas, os eritrócitos de cada tubo foram lisados com $2 \mathrm{~mL}$ de solução de lise diluída em água destilada na concentração de 1:10 (BD Biosciences) por no máximo 10 minutos e centrifugadas a $2000 \mathrm{rpm}$ por 3 minutos. Em seguida, as células brancas marcadas foram lavadas 2 vezes com $2 \mathrm{~mL}$ de solução de PBS-azida $0,1 \%$ e fixadas em $400 \mu \mathrm{L}$ de paraformaldeído a 1\% para posterior análise citométrica. 
Todos os tubos foram armazenados a $4^{\circ} \mathrm{C}$ por pelo menos 15 minutos antes da leitura no citômetro de fluxo FACSCalibur ${ }^{\mathrm{TM}}$, sendo que 30.000 células (monócitos e neutrófilos) de cada amostra foram avaliadas.

3.4. Avaliação quantitativa de monócitos e neutrófilos do sangue periférico

A avaliação quantitativa de monócitos e de neutrófilos foi feita por citometria de fluxo, após marcação sanguínea com os anticorpos murinos anti-CD14 conjugado com PerCP-Cy5.5 (vermelho forte) e anti-CD66 conjugado com isotiocianato de fluoresceína (FITC-verde), respectivamente. Duas regiões foram determinadas no gráfico dot-plot considerando o número total das populações de monócitos e de neutrófilos, respectivamente.

\subsection{Marcação do sangue periférico com anticorpo anti-HLA-B27 ligado à membrana do linfócito TCD3+}

Uma aliquota de $50 \mu \mathrm{L}$ de sangue periférico de cada paciente com APs e controle foi utilizada para detectar o HLA-B27. Após incubação com $30 \mu \mathrm{L}$ do anticorpo anti-TCD3/PE e anti-HLA-B27/FITC, o tubo de ensaio foi homogeneizado por 3 segundos e incubado durante 15 a 20 minutos à temperatura ambiente. Dois $\mathrm{mL}$ de solução de lise BD FACS foram adicionados e realizada nova incubação por no máximo 10 minutos, seguida de centrifugação a 1.200 rpm durante 5 minutos à temperatura ambiente. O sobrenadante aspirado com o auxílio de uma pipeta Pasteur acoplada à bomba a vácuo foi descartado. O tubo contendo as células marcadas foi agitado em baixa velocidade, $2 \mathrm{~mL}$ de PBS com $0,1 \%$ de azida sódica foram adicionados e seguidos de nova agitação à baixa velocidade. Após centrifugação a 
1.200 rpm por 5 minutos, o sedimento homogeneizado foi fixado com $250 \mu \mathrm{L}$ de paraformaldeído a 1\% por no mínimo 30 minutos para posterior análise citométrica.

\subsection{Citometria de Fluxo}

Todas as análises das células do sangue periférico marcadas com os monoclonais foram realizadas por citometria de fluxo. Esta metodologia avalia as múltiplas propriedades físicas e biológicas de uma célula, como seus antígenos de membrana, componentes intracitoplasmáticos e nucleares (Marti e colaboradores, 2001 [39]; Bacal e colaboradores, 2003 [40]). Para a análise das regiões de polimorfonucleares (PMN), de monócitos, do fator estimulatório de colônias de granulócitos (CD114), do fator estimulatório de granulócitos-macrófagos (CD116) e dos TLR-2 e TLR-4, as regiões foram avaliadas no gráfico de dispersão frontal e lateral, no qual se visualiza o tamanho e a granulidade de cada célula. Em cada região, PMN e monócitos foram definidos como células CD66+ ou CD14+, respectivamente. A porcentagem de células que expressam TLR-2 ou TLR-4 foi contada, sendo consideradas como positivas as células situadas no quadrante superior direito. Os limites de positividade para dot-plots no gráfico foram definidos usando anticorpos monoclonais (isotiocianato de fluoresceína - FITC; ficoeritrina PE e complexo proteína peridinina-clorofila PerCP) como controles isotípicos.

Todos os reagentes foram utilizados à temperatura ambiente, protegidos da luz direta, e todas as amostras foram analisadas no aparelho FACSCalibur Analyser Becton Dickinson. Os ajustes iniciais nas voltagens dos fotomultiplicadores dos detectores de dispersão da luz frontal (FSC) e lateral (SSC) foram realizados com os controles isotípicos. Em seguida, com os controles positivos (TCD3+, TCD4+ e TCD8+), foram realizadas as compensações dos fotodetectores de fluorescência-1 
(FL-1), fluorescência-2 (FL-2) e fluorescência-3 (FL-3), capazes de detectar comprimentos de onda de $494 \mathrm{~nm}$ e $517 \mathrm{~nm}$ emitidos pelo fluorocromo FITC (verde), de $565 \mathrm{~nm}$ e $660 \mathrm{~nm}$ emitidos pelo fluorocromo PE (amarelo), de $670 \mathrm{~nm}$ emitidos pelo PerCp (vermelho) e de $488 \mathrm{~nm}$ emitidos pelo Alexa Fluor $\AA$ (verde), respectivamente. Estes ajustes são necessários para corrigir a superposição dos espectros de fluorescência emitidos por FITC, PE, PerCp e Alexa Fluor®. As células mononucleares foram aspiradas pelo sistema fluido e individualmente excitadas pelo feixe de raios laser. À medida que as células foram excitadas pelo laser, elas absorveram a energia do laser e a emitiram em forma de comprimento de ondas (fluorescências). As ondas de energia ou sinais de luz passavam pelo sistema óptico constituído de espelhos e filtros de luz e eram conduzidos para os fotodetectores FL1, FL-2 e FL-3. Concomitantemente, o detector FSC captava a luz dispersa na direção frontal do laser, que corresponde ao tamanho da célula. O detector SSC, situado em ângulo reto com o laser, captava a luz dispersa lateralmente, reflexo de complexidade interna das células e de sua granulidade. Todos os sinais ópticos foram amplificados e transformados em sinais eletrônicos, convertidos em valores digitais, quantificados e enviados para análise digital no computador do citômetro de fluxo [39,40,41], utilizando o programa CellQuest TM (BD Biosciences).

Para análise do HLA-B27, a leitura no citometro de fluxo foi feita usando o software $\mathrm{BD}^{\mathrm{TM}}$ HLA-B27 e a região dos linfócitos foi avaliada no gráfico de dispersão frontal e lateral, na qual se visualiza o tamanho e a granulidade de cada célula nas células TCD3+. Em seguida, a porcentagem de células que expressam TCD3+/HLAB27+ foi visualizada, sendo consideradas como positivas as células no quadrante 
superior direito. Os limites de positividade para dot- plots no gráfico foram definidos usando controles isotípicos.

\subsection{Análise estatística}

A análise estatística foi realizada pelo programa Windows ${ }^{\circledR}$ SPSS 15,0 para pacote de software estatístico (Chicago, IL, EUA). A comparação entre grupos utilizando o teste $U$ de Mann-Whitney e os resultados expressos em porcentagem como média \pm intervalo interquartil, de acordo com uma distribuição não-paramétrica, avaliados pelo teste de Shapiro-Wilk. Na análise do HLA-B27 entre os grupos positivos e negativos, utilizamos o software GraphPad Prism 6.0 pelo teste de Fisher.

Os valores de $p<0,05$ foram considerados significativos. 
RESULTADOS 


\section{Resultados}

\subsection{Características demográficas dos pacientes com APs}

Quarenta e cinco pacientes com APs, 22 mulheres e 23 homens, com média de idade de $52 \pm 13$ anos e duração média da doença de $15 \pm 10$ anos e 32 indivíduos saudáveis, 17 mulheres e 15 homens, com média de idade $33 \pm 7$ anos incluídos como grupo controle foram analisados. Vinte e sete pacientes foram classificados como tendo APs ativa (média do DAS28 > 3,75), duração média da doença de $14 \pm 9$ anos e 18 pacientes como APs inativa (média do DAS28 < 1,76) com duração medida da doença $17 \pm 11$ anos $(p>0,91)$.

4.2. Expressão dos receptores TLR-2 e TLR-4 ligados à membrana de monócitos e neutrófilos do sangue periférico de pacientes com APs, APs ativa, APs inativa e controles (Tabelas 1 e 2, Figuras 2 e 3 )

A Tabela 1 mostra a expressão do TLR-2 em monócitos e em neutrófilos de pacientes com APs e controles. Nos monócitos, a expressão do TLR2 nos pacientes com APs, APs ativa, APs inativa e indivíduos sadios foi $89 \pm 17 \%$; $90 \pm 17 \%$; $86 \pm$ $18 \%$ e $71 \pm 49 \%$, respectivamente, sendo maior nos pacientes com APs, tanto com doença ativa como naqueles com APs inativa quando comparados aos controles ( $p=0,002, p=0,001$ e $p=0,004)$. Ainda, a expressão do TLR-2 nos monócitos foi similar nos pacientes com APs ativa e APs inativa (90 $\pm 17 \%$ vs $86 \pm 18 \%, p=0,10)$. Em neutrófilos, a expressão do TLR-2 foi similar nos pacientes com APs, APs ativa, APs inativa e indivíduos sadios: $6 \pm 29 \% ; 6 \pm 39 \% ; 8 \pm 24 \%$ e $18,50 \pm 31 \%$, respectivamente $(p=0,07, p=0,15$ e $p=0,10)$. Não houve diferença na expressão do 
TLR-2 em neutrófilos de pacientes com APs ativa comparados aos com APs inativa (6 $\pm 9 \%$ vs. $8 \pm 24 \%, p=0.74)$.

Em relação à expressão do TLR-4, a Tabela 2 demonstra que foi similar em ambos - monócitos e neutrófilos - de pacientes com APs e controles, tanto nos com APs ativa, quanto nos com APs inativa.

Tabela 1. Expressão do TLR-2 em monócitos e neutrófilos do sangue periférico de pacientes com APs, APs ativa, APs inativa e controles.

\section{TLR-2}

\begin{tabular}{lcc}
\hline & Monócitos (\%) & Neutrófilos (\%) \\
\hline APs vs controles & $89 \pm 17$ vs $71 \pm 49$ & $6 \pm 29$ vs $18 \pm 31$ \\
& $p=0,002^{*}$ & $p=0,07$ \\
APs ativa vs controle & $90 \pm 17$ vs $71 \pm 49$ & $6 \pm 39$ vs $18 \pm 31$ \\
& $p=0,001^{*}$ & $p=0,15$ \\
APs inativa vs controle & $86 \pm 18$ vs $71 \pm 49$ & $8 \pm 24$ vs $18,50 \pm 31$ \\
& $p=0,04^{*}$ & $p=0,10$ \\
APs ativa vs APs inativa & $90 \pm 17$ vs $86 \pm 18$ & $5 \pm 39$ vs $8 \pm 24$ \\
& $p=0,10$ & $p=0,74$ \\
\hline APs: Artrite psoriásica. & & ${ }^{*}$ Teste $U$ de Mann-Whitney, $p<0.05$.
\end{tabular}


Tabela 2. Expressão do TLR-4 em monócitos e neutrófilos do sangue periférico de pacientes com APs, APs ativa, APs inativa e controles.

\section{TLR-4}

\begin{tabular}{lcc}
\hline & Monócitos (\%) & Neutrófilos (\%) \\
\hline APs vs controles & $2 \pm 9$ vs $1 \pm 3$ & $2 \pm 9$ vs $1 \pm 3$ \\
& $p=0,23$ & $p=0,48$ \\
APs ativa vs controle & $2 \pm 4$ vs $1 \pm 3$ & $2 \pm 7$ vs $1 \pm 3$ \\
APs inativa vs controle & $p=0,33$ & $p=0,69$ \\
& $2 \pm 15$ vs $1 \pm 3$ & $2 \pm 11$ vs $1 \pm 3$ \\
APs ativa vs APs inativa & $2 \pm 4$ vs $2 \pm 15$ & $2 \pm 7$ vs $2 \pm 11$ \\
& $p=0,83$ & $p=0,66$ \\
\hline APs: Artrite psoriásica. & & ${ }^{*}$ Teste U de Mann-Whitney, $p<0.05$.
\end{tabular}

Por meio de dot-plot e histograma, as Figuras 2 e 3 representam, respectivamente, as leituras das expressões do TLR-2 e do TLR-4 na membrana de monócitos e neutrófilos de 1 paciente com APs e 1 controle. 


\section{Paciente}
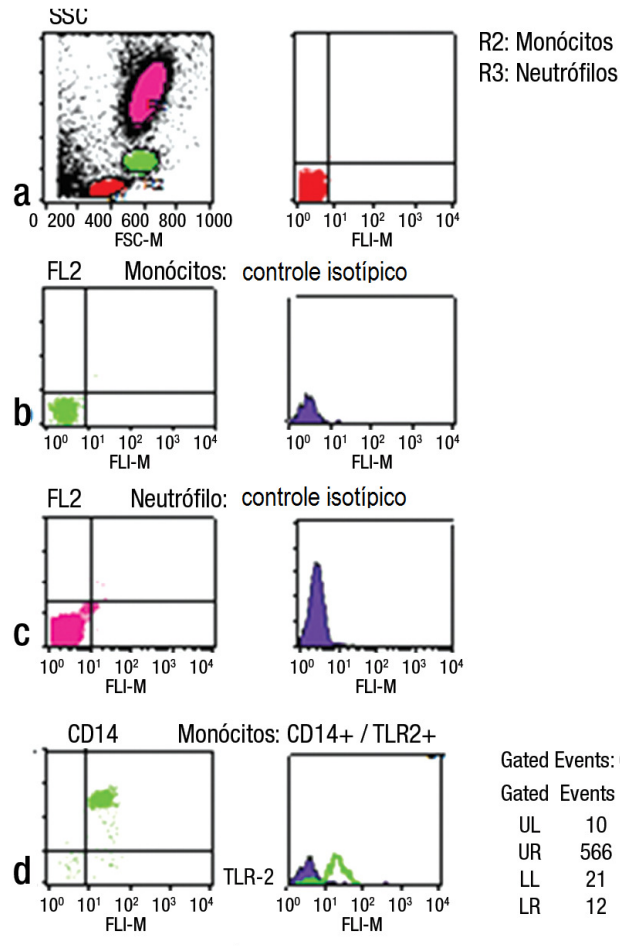

Gated Events: 609 Total Events: 30.000

Gated Events \%Gated \%Total

$\begin{array}{llll}\text { UL } & 10 & 1.64 & 0.03\end{array}$

$\begin{array}{llll}\text { UR } & 566 & 92.94 & 1.89\end{array}$

$\begin{array}{llll}\mathrm{LL} & 21 & 3.45 & 0.07\end{array}$

$\begin{array}{llll}\mathrm{LR} & 12 & 1.97 & 0.04\end{array}$

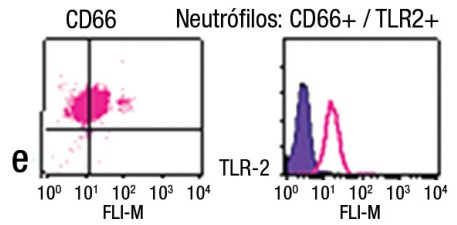

Gated Events: 13905 Total Events: 30.000

Gated Events \%Gated \%Total

$\begin{array}{llll}\text { UL } & 4313 & 31.02 & 14.33\end{array}$

$\begin{array}{llll}\text { UR } & 9553 & 63.70 & 31.84\end{array}$

$\begin{array}{lccc}\text { LL } & 23 & 0.17 & 0.03 \\ \text { LR } & 17 & 0.12 & 0.05\end{array}$

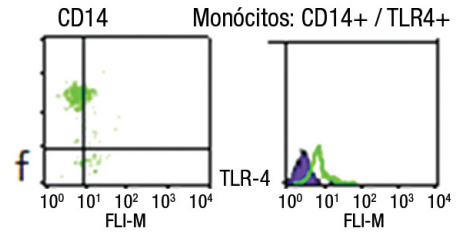

Gated Events: 591 Total Events: 30.000

Gated Events \%Gated \%Total

$\begin{array}{llll}\text { UL } & 477 & 80.71 & 1.59\end{array}$

$\begin{array}{llll}\text { UR } & 69 & 11.68 & 0.23\end{array}$

$\begin{array}{cccc}\mathrm{UR} & 69 & 11.68 & 0.23 \\ \mathrm{LL} & 15 & 2.54 & 0.05\end{array}$

$\begin{array}{llll}\mathrm{LL} & 15 & 2.54 & 0.05 \\ \mathrm{LR} & 30 & 5.03 & 0.10\end{array}$

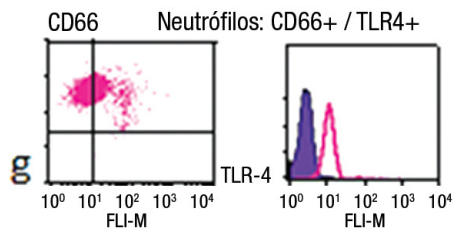

Gated Events: 11581 Total Events: 30.000

Gated Events \%Gated \%Total

$\begin{array}{llll}\text { UL } & 7170 & 61.69 & 23.90\end{array}$

$\begin{array}{llll}\text { UR } & 4402 & 33.01 & 14.67\end{array}$

$\begin{array}{cccc}\mathrm{LL} & 2 & 0.02 & 0.01 \\ \mathrm{LR} & 7 & 0.05 & 0.02\end{array}$

Figura 2. Citometria de fluxo de um paciente com artrite psoriásica: a) gráfico de dispersão dos leucócitos periféricos de acordo com tamanho e granulosidade; b) definição dos quadrantes (limites de positividade) de acordo com distribuição de monócitos incubados com controle isotípico; c) definição de quadrantes (limites de positividade) de acordo com distribuição de neutrófilos incubados com controle isotípico; d) expressão de TLR-2 (eixo horizontal) e de CD14 (eixo vertical) por monócitos; e) expressão de TLR-2 (eixo horizontal) e de CD66 (eixo vertical) por neutrófilos; f) a expressão de TLR-4 (eixo horizontal) e CD14 (eixo vertical) por monócitos; g) a expressão de TLR-4 (eixo horizontal) e CD66 (eixo vertical) por neutrófilos. A porcentagem de células (monócitos ou neutrófilos) no quadrante superior direito foi considerada como uma medida da expressão TLR. 


\section{Controle}
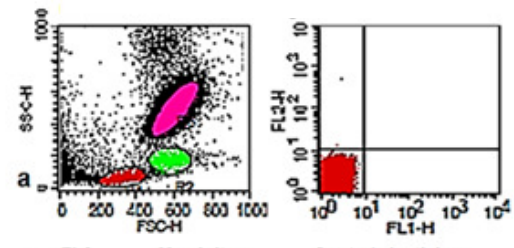

R2: Monócitos

R3: Neutrófilos
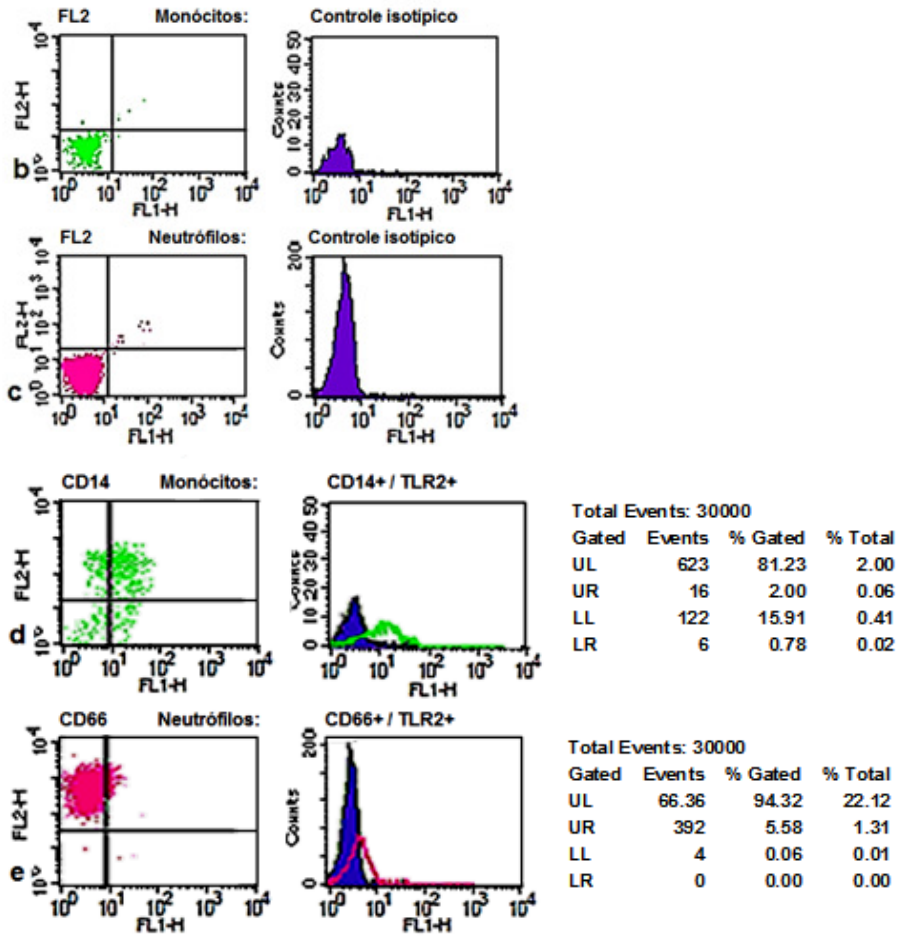

Total Events: $\mathbf{3 0 0 0 0}$

Gated Events \% Gated \% Total

$\begin{array}{llll}\text { UL } & 66.36 & 94.32 & 22.12\end{array}$

UR $\quad 392 \quad 5.58$

$\begin{array}{llll}\text { LL } & 4 & 0.06 & 0.01\end{array}$
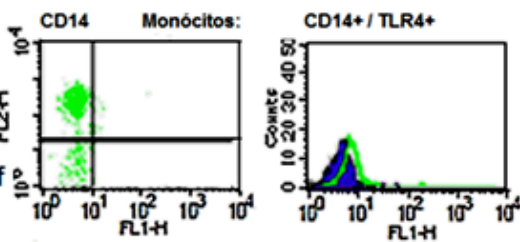

Total Events: 30000

Gated Events \%Gated \% T otal

$\begin{array}{lrrr}\text { Gated } & \text { Events } & \% \text { Gated } & \% \text { Total } \\ \text { UL } & 152 & 24.25 & 0.54\end{array}$

$\begin{array}{llll}\text { UR } & 389 & 56.23 & 1.30\end{array}$

$\begin{array}{lrrr}\text { LL } & 65 & 9.73 & 0.22\end{array}$

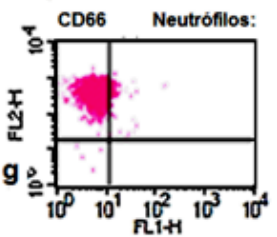

CD66+ / TLR4+

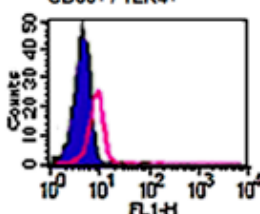

Total Events: 30000

Gated Events \% Gated \% Total

UL $\quad 5857 \quad 91.85$

UR

$\begin{array}{llll}\text { LL } & 1 & 0.02 & 0.00\end{array}$

Figura 3. Citometria de fluxo de um controle: a) gráfico de dispersão dos leucócitos periféricos de acordo com tamanho e granulosidade; b) definição dos quadrantes (limites de positividade) de acordo com distribuição de monócitos incubados com controle isotípico; c) definição de quadrantes (limites de positividade) de acordo com distribuição de neutrófilos incubados com controle isotípico; d) expressão de TLR-2 (eixo horizontal) e de CD14 (eixo vertical) por monócitos; e) expressão de TLR-2 (eixo horizontal) e de CD66 (eixo vertical) por neutrófilos; f) a expressão de TLR-4 (eixo horizontal) e CD14 (eixo vertical) por monócitos; g) a expressão de TLR-4 (eixo horizontal) e CD66 (eixo vertical) por neutrófilos. A porcentagem de células (monócitos ou neutrófilos) no quadrante superior direito foi considerada como uma medida da expressão TLR. 
4.3. Expressão dos receptores CD114 e CD116 ligados à membrana de monócitos e neutrófilos do sangue periférico de pacientes com APs, APs ativa, APs inativa e controles (Tabelas 3 e 4)

A expressão do CD114 (G-CSF) em monócitos e neutrófilos foi semelhante em pacientes com APs, APs ativa, APs inativa e controles, conforme mostrado na Tabela 3. Da mesma forma, a expressão do CD116 (GM-CSF) também foi similar nos pacientes com APs, APs ativa, APs inativa e controles (Tabela 4).

Tabela 3. Expressão do CD114 em monócitos e neutrófilos de pacientes com APs, APs ativa, APs inativa e controles.

\begin{tabular}{lllll}
\hline \multicolumn{1}{c}{ CD114 } & Monócitos (\%) & $\boldsymbol{p}$ & Neutrófilos (\%) & $\boldsymbol{p}$ \\
\hline APs vs controles & $67 \pm 18$ vs $51 \pm 24$ & 0,06 & $95 \pm 19$ vs $93 \pm 20$ & 0,74 \\
\hline APs ativa vs controles & $71 \pm 13$ vs $51 \pm 24$ & 0,09 & $90 \pm 28$ vs $93 \pm 20$ & 0,99 \\
\hline APs inativa vs controles & $64 \pm 22$ vs $51 \pm 24$ & 0,13 & $99 \pm 1$ vs $93 \pm 20$ & 0,62 \\
APs ativa vs APs inativa & $71 \pm 13$ vs $64 \pm 22$ & 0,73 & $90 \pm 28$ vs $99 \pm 1$ & 0,70 \\
\hline
\end{tabular}


Tabela 4. Expressão do CD116 em monócitos e neutrófilos de pacientes com APs, APs ativa, APs inativa e controles.

\begin{tabular}{llllll}
\hline \multicolumn{1}{c}{ CD116 } & Monócitos (\%) & $\boldsymbol{p}$ & Neutrófilos (\%) & p \\
\hline APs vs controle & $32 \pm 20$ vs $48 \pm 30$ & 0,25 & $79 \pm 25$ vs $81 \pm 17$ & 0,25 \\
\hline APs ativa vs controles & $33 \pm 39$ vs $48 \pm 30$ & 0,27 & $77 \pm 17$ vs $81 \pm 17$ & 0,25 \\
\hline APs inativa vs controles & $37 \pm 29$ vs $48 \pm 30$ & 0,35 & $81 \pm 17$ vs $81 \pm 17$ & 0,23 \\
& & & & \\
APs ativa vs APs inativa & $33 \pm 39$ vs $37 \pm 29$ & 0,95 & $77 \pm 17$ vs $81 \pm 17$ & 0,25 \\
\hline APs: Artrite psoriásica. & & & & \\
\hline
\end{tabular}

4.4. Avaliação numérica de monócitos e neutrófilos no sangue periférico de pacientes com APs, APs ativa, APs inativa e controles (Tabela 5)

Por meio da citometria de fluxo, a contagem de monócitos de pacientes com APs, APs ativa, APs inativa e indivíduos sadios foi de $999 \pm 437$; $1.043 \pm 506 ; 934 \pm$ 310 e $656 \pm 402$, respectivamente, sendo estatisticamente maior nos pacientes com APs, tanto com doença ativa como naqueles com APs inativa, quando comparados aos controles $(p<0,01)$. Da mesma forma, os números absolutos de neutrófilos também foram significativamente maiores nos pacientes com APs, tanto APs ativa quanto APs inativa, quando comparados aos controles $(15.271 \pm 5.162 ; 15.898 \pm$ 5.149 e $14.329 \pm 5.180 ; 9.417 \pm 5.789) p<0,001$. A contagem de monócitos e neutrófilos entre os pacientes com APs ativa comparados a APs inativa foram similares $(1.043 \pm 506 ; 934 \pm 310$ e $15.898 \pm 5.149 ; 14.329 \pm 5.180) p>0,96$ e $p>0,39$, respectivamente. 
Tabela 5. Comparação quantitativa do número de monócitos e neutrófilos do sangue periférico, por citometria de fluxo, de pacientes com APs, APs ativa, APs inativa e controles.

\begin{tabular}{ccc}
\hline APs & Monócitos $(\mathbf{n})$ & Neutrófilos $(\mathbf{n})$ \\
\hline APs vs controles & $999 \pm 437$ vs $657 \pm 402$ & $15271 \pm 5162$ vs $9417 \pm 5789$ \\
$\mathbf{n}=\mathbf{4 5 / 3 2}$ & $p<0,0003^{*}$ & $p<0,0001^{*}$ \\
APs ativa vs inativa & $1043 \pm 506$ vs $934 \pm 310$ & $15898 \pm 5149$ vs $14329 \pm 5180$ \\
$\mathbf{n}=\mathbf{2 7 / 1 8}$ & $p=0,96$ & $p=0,39$ \\
APs ativo vs controles & $1043 \pm 506$ vs $656 \pm 402$ & $15898 \pm 5149$ vs $9417 \pm 5789$ \\
$\mathbf{n}=\mathbf{2 7 / 3 2}$ & $p<0,0008^{*}$ & $p<0,0001^{*}$ \\
APs inativos vs & $934 \pm 310$ vs $656 \pm 402$ & $14329 \pm 5180$ vs $9417 \pm 5789$ \\
controles $\mathbf{n}=\mathbf{1 8} / \mathbf{3 2}$ & $p<0,01^{*}$ & $p<0,0001^{*}$
\end{tabular}

APs: Artrite psoriásica.

${ }^{*}$ Teste Mann-Whitney $\mathrm{U}, p<0.05$

4.5. Expressão do antígeno HLA-B27 ligado à membrana de linfócitos TCD3+ (Figura 4)

Dentre os 45 pacientes que participaram deste estudo, o teste para analisar a expressão do HLA-B27 foi feito em 37, estando presente em 12 (32\%), sendo que $3(25 \%)$ e $9(75 \%)$ tinham acometimento da doença (periférica e axial + periférica respectivamente. Na amostra de 32 controles, a positividade foi de 2/32 (6\%) $(p<0,01)$.

Além destes 45 pacientes, a expressão do HLA-B27 foi realizada em outros 104 sujeitos com APs pertencentes ao nosso serviço de reumatologia do HCFMUSP, sendo positivo em 30, ou seja 29\%. Desta forma, a positividade total do HLA-B27 dentre os 141 pacientes com APs foi de 29,8\%. De acordo com os subtipos clínicos de doença entre estes 141 pacientes, o HLA-B27 foi positivo em 26\% (22/85) dos pacientes com APs periférica, 37\% (17/46) dos pacientes com doença axial e periférica e 30\% (3/10) daqueles com envolvimento axial isolado. 
$\mathrm{Na}$ Figura 4, observa-se dados citométricos representativos da expressão do HLA-B27 em 1 controle e em 1 paciente com APs, respectivamente.
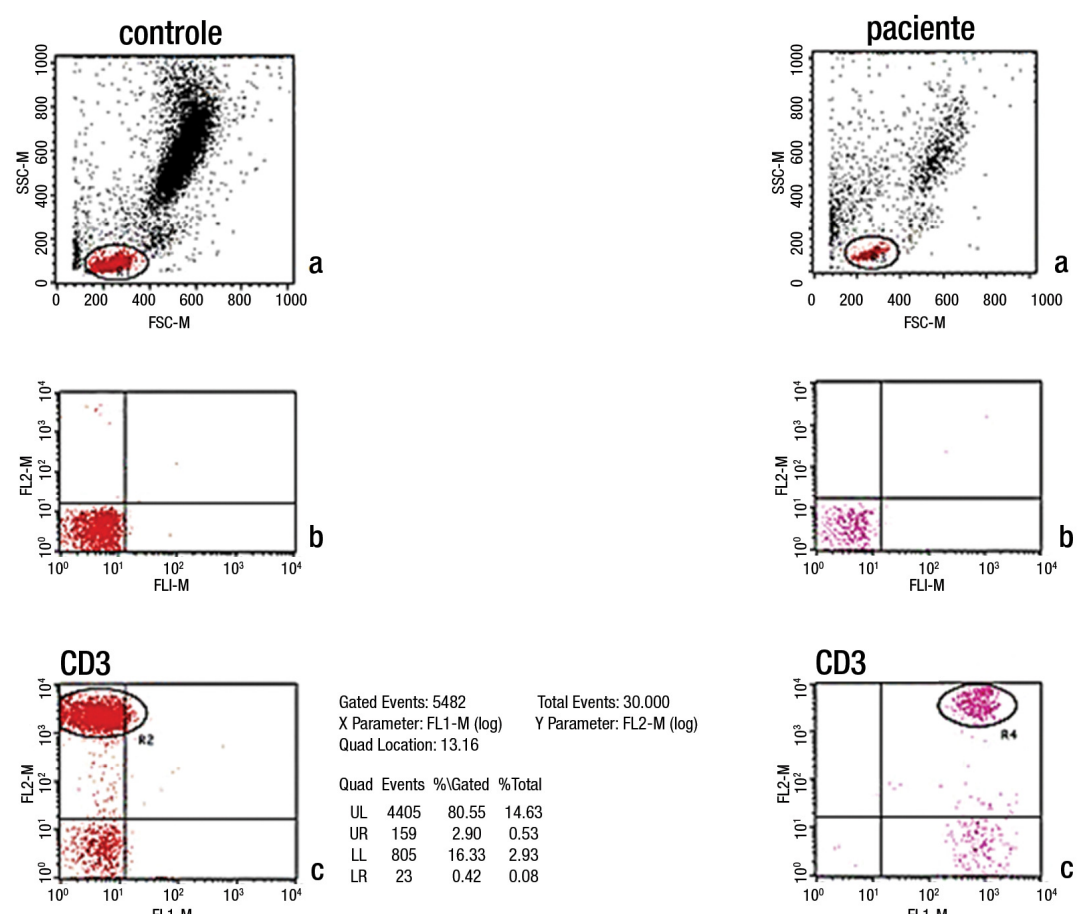

HLA-B27

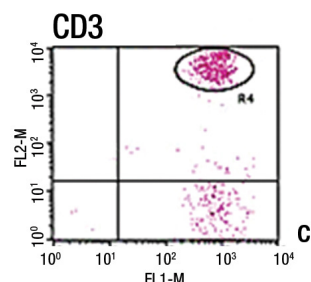

Gated Events: $890 \quad$ Total Events: 5070 X Parameter: FL1-M (log) Y Parameter: FL2-M (log) HLA-B27

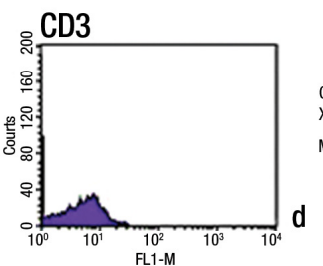

$$
\begin{array}{ll}
\text { Gated Events: } 4550 & \text { Total Events: } 30.000 \\
\text { X Parameter: FL1-M (log) }
\end{array}
$$

Marker Left, Right Events \%Gated \%Total Peak Ch A1 $\quad \begin{array}{lllll}1,9010 & 4650 & 100.00 & 15.50 & 1\end{array}$

HLA-B27

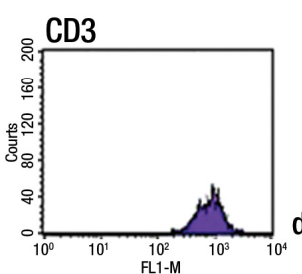

HLA-B27
Gate: G4 Total Events: 5070

rameter: FL1-M (log)

Marker Left, Right Events \%Gated \%Total Peak Ch

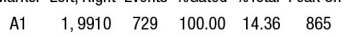

Figura 4. Citometria de fluxo de um controle e de um paciente com artrite psoriásica: a) gráfico de dispersão dos leucócitos periféricos de acordo com tamanho e granulosidade; b) definição dos quadrantes (limites de positividade), de acordo com distribuição de linfócitos incubados com controle isotípico; c) expressão do anticorpo HLA-B27 no eixo horizontal e CD3 no eixo vertical; d) expressão de CD3/HLA-B27 representada por histograma. A porcentagem de células CD3/HLA-B27 no quadrante superior direito foi considerada como uma medida da expressão do HLA-B27.

\subsection{Expressão do TLR-2 em monócitos de pacientes com APs HLA-B27+} comparados aos controles HLA-B27+

Nos pacientes com APs HLA-B27+ comparados aos controles HLA-B27+, a porcentagem de expressão do TLR-2 nos monócitos foi significantemente maior $(p<0,004)$. 
DISCUSSÃO 


\section{Discussão}

Este estudo demonstrou pela primeira vez aumento da expressão do TLR-2 em monócitos de pacientes com APs, independentemente da atividade da doença, sugerindo associação preferencial com bactérias Gram-positivas. De maneira similar, a expressão do TLR-2 também foi maior nos pacientes com APs HLA-B27+, reforçando a importância destes receptores na ativação do sistema imune inato.

Nos monócitos dos pacientes com APs, APs ativa e APs inativa, a expressão do TLR-2 foi significativamente maior quando comparados aos controles. Entre pacientes com APs ativa e APs inativa não houve diferença significativa, sugerindo que o aumento da expressão do TLR-2 é independente da atividade da doença. Em neutrófilos, a expressão do TLR-2 foi similar nos pacientes com APs, APs ativa, APs inativa e indivíduos saudáveis. Uma possibilidade para explicar esta discrepância dos achados de expressão do TLR-2 nos monócitos e neutrófilos talvez seja o tamanho da amostra. Não houve diferença na expressão do TLR-2 em neutrófilos de pacientes com APs ativa comparados aos pacientes com APs inativa. Neste sentido, recentes pesquisas apontam para o potencial papel dos TLRs em uma variedade de doenças inflamatórias (lúpus eritematoso sistêmico, artrite reumatoide, esclerose sistêmica, gota e outras) $[28,30,42,43]$. A detecção do TLR-2 nos pacientes com APs indica que houve estimulação da resposta imunológica inata, provavelmente ativada no início da doença e desencadeada por ácidos lipoteicóicos presentes na parede de bactérias Gram-positivas.

Corroborando com estes achados, Candia e colaboradores (2007) relataram que a expressão do TLR-2 foi significativamente elevada em células dendríticas 
imaturas obtidas a partir de culturas de monócitos de pacientes com APs ativa estimulados com GM-CSF e IL-4, sugerindo que bactérias Gram-positivas desencadeiam a alta expressão do TLR-2, contribuindo para o processo imunopatogênico envolvido na doença articular relacionada à psoríase [37]. Entretanto, Candia e colaboradores não encontraram diferença de expressão do TLR2 nos monócitos circulantes, provavelmente devido ao pequeno número de pacientes avaliados $(n=10)$ [37]. Em psoríase na qual o envolvimento da pele precede a artrite em até $75 \%$ dos casos [7], alguns autores relataram alta expressão de TLR-2 na pele destes pacientes, sugerindo que bactérias Gram-positivas, tais como estreptococos, podem ter um papel indutor relevante na doença [21, 22].

Histologicamente, a APs é caracterizada por infiltração de linfócitos T e B, macrófagos e células dendríticas associado com aumento da proliferação de neutrófilos e angiogênese [52]. Os neutrófilos tem papel importante no desenvolvimento da placa psoriásica participando da angiogênse [47,44]. Toichi e colaboradores (2000) [45] relataram nas placas psoriásicas e no sangue periférico redução do número de neutrófilos após administração de ticlopidina (antiagregante plaquetário) com aparecimento de novas placas e aumento na contagem dos neutrófilos quando a medicação foi suspensa. Além do envolvimento dos neutrófilos, estudos clínicos e experimentais indicam que a inflamação mediada por monócitosmacrófagos é um fator-chave na estimulação de queratinócitos e hiperproliferação de sinoviócitos [citado pelo 31]. Embora indivíduos normais expressem constitutivamente TLR-2 em queratinócitos epidérmicos, estudos em psoríase mostraram que as lesões psoriásicas na pele têm expressão aumentada deste receptor em comparação com a 
pele normal [47], enquanto que não foi observada diferença na expressão do TLR-3 e TLR-4 [34,47].

Em relação à expressão do TLR-4, a porcentagem foi similar em ambos monócitos e neutrófilos - de pacientes com APs e controles, tanto nos com APs ativa, quanto nos com APs inativa, sugerindo que bactérias Gram-negativas não devam participar na patogênese da APs. Entretanto, Garcia e colaboradores (2011), em PsO, evidenciaram o aumento na expressão do gene TLR-4 em células mononucleares do sangue periférico, porém não avaliaram a expressão do TLR-4 na membrana [33]. Em células dendríticas de pacientes com doença psoriásica, os TLR-2 e os TLR-4 estavam aumentados [34] e em outras formas de espondiloartrites, como a espondilite anquilosante (EA), ambos foram altamente expressos em monócitos do sangue periférico [48]. Interessantemente, a artrite reativa é claramente desencadeada por uma infecção gastrointestinal bacteriana por Salmonella, Yersínia, Campylobacter e Shiguella, ou urogenital (Chlamydia trachomatis) [49], bactérias Gram-negativas que contenham em suas paredes LPS que são reconhecidos pelos TLR-4.

A expressão do CD114 (receptor de G-CSF) em monócitos e neutrófilos foi semelhante em pacientes com APs, APs ativa, APs inativa e controles. Da mesma forma, a expressão do CD116 (receptor de GM-CSF) também foi similar nos pacientes com APs, APs ativa, APs inativa e controles. Monócitos e neutrófilos desempenham um importante papel na resposta inflamatória por meio da produção de moléculas específicas envolvidas na resposta imune [31]. A produção e a liberação de G-CSF são estimuladas por LPS presente em bactérias Gram-negativas [53]. LPS e G-CSF funcionam como estímulo primário na ativação de neutrófilos por meio da sua interação com TLR-2 e com o receptor CD114, respectivamente, promovendo a 
produção e liberação de GM-CSF. Estudos in vitro mostram que monócitos são ativados por TRL-2, mas a presença de GM-CSF aumenta a resposta de monócitos e neutrófilos [53]. Quando ocorre a ligação do G-CSF ao receptor CD114, há uma diminuição dos receptores disponíveis, uma vez que esse complexo proteína-receptor é internalizado e degradado [54], sendo uma possível explicação para nossos resultados. Possivelmente, os G-CSF e GM-CSF solúveis estão sendo liberados nos monócitos e neutrófilos ativados, estimulando a medula óssea a produzir precursores de monócitos e neutrófilos. Futuramente, dosagens dos fatores de crescimento G-CSF e GM-CSF solúveis talvez possam ajudar a esclarecer nossos achados.

O número total de monócitos e neutrófilos foi significativamente maior nos pacientes com APs comparados aos nossos controles. Estudos clínicos e experimentais indicam que a inflamação mediada por monócitos-macrófagos é um fator-chave na estimulação de queratinócitos e hiperproliferação de sinoviócitos [citado pelo 31]. Toichi e colaboradores (2000) observaram que os neutrófilos estão aumentados nas placas psoriásicas e no sangue periférico [45], corroborando com nossos achados e enfatizando o envolvimento da imunidade inata na APs com a participação de monócitos e neutrófilos.

Dentre os 37 pacientes que analisamos, a expressão do HLA-B27 foi positiva em 12 (32\%), sendo que $3(25 \%)$ e 9 (75\%) tinham acometimento da doença (periférica e axial + periférica, respectivamente). Como o quadro clínico era sobretudo periférico e com a intenção de diferenciar o índice de atividade da doença, utilizamos o escore de atividade de doença DAS28, exluindo os pacientes com envolvimento puramente axial. A frequência de HLA-B27+ em nosso estudo foi similar à literatura mundial (20\% a 60\%) [1] e na população brasileira $(20,6 \%$ a $36,4 \%)$ [19,20]. A 
importância da associação do HLA-B27 e bactérias foi demonstrada em modelo murino transgênico HLA-B27+, em que o estado livre de germe impede o desenvolvimento de características de EpA [48]. Propõe-se que os produtos microbianos sejam apresentados para linfócitos TCD8+ no contexto do HLA-B27+ por células apresentadoras de antígeno, iniciando assim a resposta inflamatória em humanos [49]. Adicionalmente, a expressão do TLR-2 foi maior nos monócitos de pacientes HLA-B27+ em comparação com indivíduos saudáveis HLA-B27+, indicando o possível papel destes receptores na patogênese da APs. Em AR, o HLA-B27 está associado com o aumento da invasão de Salmonella nas células epiteliais [55], sugerindo que o HLA-B27 é fortemente associado à infecção [6]. Em murinos com AR, fagócitos mononucleares foram responsáveis pela disseminação extraintestinal de Salmonella [56] e fibroblastos podem servir como reservatório para micróbios [57].

Em conclusão, a alta expressão do TLR-2 em monócitos de pacientes com APs sugere o papel de micro-organismos Gram-positivos como um gatilho na resposta inflamatória nesta doença. Estudos posteriores são necessários para esclarecer o significado patológico da estimulação do TLR na APs. 
CONCLUSÕES 


\section{Conclusões}

1) Pela primeira vez demonstramos aumento da expressão do TLR-2 em monócitos de pacientes com APs, reforçando o papel do sistema imune inato e a possível participação de bactérias Gram-positivas na patogênese da APs.

2) O aumento da expressão do TLR-2 em monócitos de pacientes com APs ativa e inativa sugere que esta seja uma característica da própria doença independente da sua atividade clínica.

3) A expressão de TLR-4 em monócitos e neutrófilos similar em pacientes com APs e controles sugere que bactérias Gram-negativas não devam participar na patogênese da doença.

4) Expressão similar do CD114 e do CD116 (receptores de G-CSF e GMCSF, respectivamente) entre pacientes com APs e controles normais.

5) Aumento de expressão de TLR-2 em monócitos de pacientes com APs HLA-B27+ sugere importante papel destes receptores na patogênese da APs, assim como também da imunidade inata.

6) A prevalência de HLA-B27 nos nossos pacientes com APs é semelhante ao descrito na literatura mundial e brasileira. 
ANEXOS 


\section{Anexos}

\section{Anexo A - CASPAR criteria}

\section{The CASPAR criteria}

To meet the CASPAR (CIASsification criteria for Psoriatic ARthritis) criteria, a patient must have inflammatory articular disease (joint, spine, or entheseal) with $\geq 3$ points from the following 5 categories:

1. Evidence of current psoriasis, a personal history of psoriasis, or a family history of psoriasis.

Current psoriasis is defined as psoriatic skin or scalp disease present today as judged by a rheumatologist or dermatologist. ${ }^{ \pm}$

A personal history of psoriasis is defined as a history of psoriasis that may be obtained from a patient, family physician, dermatologist, rheumatologist, or other qualified health care provider.

A family history of psoriasis is defined as a history of psoriasis in a first- or second-degree relative according to patient report.

2. Typical psoriatic nail dystrophy including onycholysis, pitting, and hyperkeratosis observed on current physical examination.

3. A negative test result for the presence of rheumatoid factor by any method except latex but preferably by enzyme-linked immunosorbent assay or nephelometry, according to the local laboratory reference range.

4. Either current dactylitis, defined as swelling of an entire digit, or a history of dactylitis recorded by a rheumatologist.

5. Radiographic evidence of juxtaarticular new bone formation, appearing as ill-defined ossification near joint margins (but excluding osteophyte formation) on plain radiographs of the hand or foot.

${ }^{*}$ The CASPAR criteria have specificity of $98.7 \%$ and sensitivity of $91.4 \%$.

†Current psoriasis is assigned a score of 2; all other features are assigned a score of 1.

Taylor W, Gladman D, Helliwell P, et al. Arthritis Rheum 2006;54:2665-73 
Anexo B - Figura representativa da contagem de 28 articulações (DAS 28)

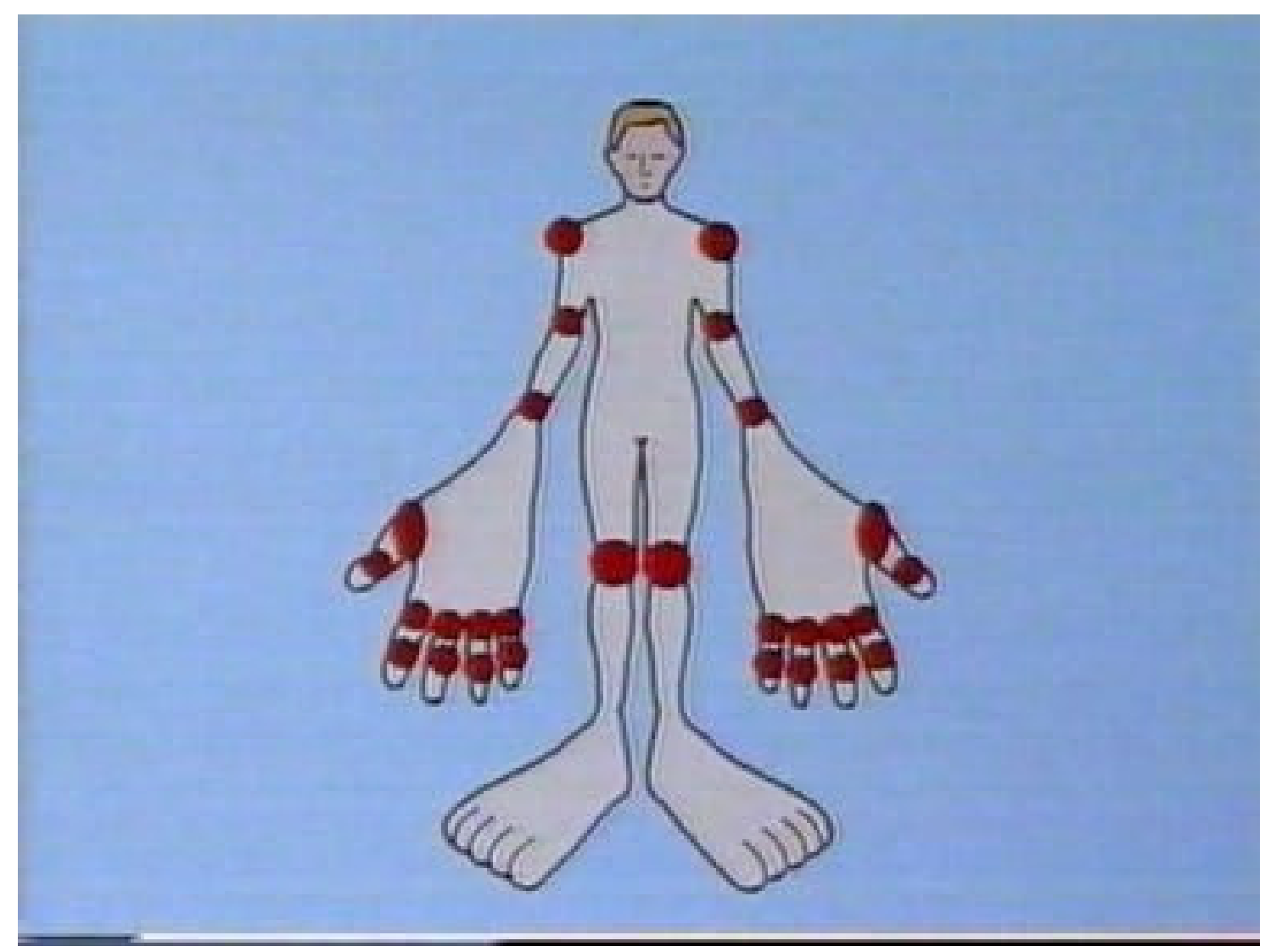

Prevoo Mll, Van’t Hoff MA et al. J Rheumatol 1997;24:1477-85. 
REFERÊNCIAS 


\section{Referências}

1. MOLL JM, WHIGHT V. PSORIATIC ATHRITIS. Seimin Arthrithis Rheumatol. 1973;3:55-78.

2. DAFNA D GLADMAN. Psoriatic arthritis. Dermatologia therapy. 2009; vol.22:40-55.

3. ALAMANOS Y, VOULGARI PV, DROSOS AA. Incidence and prevalence of psoriatic arthritis: a systematic review. J Rheumatol. 2008;Jul;35(7):1354-8. Epub 2008 May 1.

4. WILSON FC, ICEN M, CROWSON CS, MCEVOY MT, GABRIEL SE, KREMERS HM. Time trends in epidemiology and characteristics of psoriatic arthritis over 3 decades: a population-based study. J Rheumatol. 2009;Feb;36(2):361-7.

5. TRONTZAS T, ANDRIANA KOS A, MIYAKIS S, et al. Seronegative spondyloarthropaties in Greece: a population-based study of prevalence, clinical pattern and management. The ESORDIG study. Clin Rheumatol. 2005; $24(6): 583-9$.

6. GLADMAN DD, ANTONI C, MEASE P, CLEGG DO, NASH P. Psoriatic arthritis: epidemiology, clinical features, course, and outcome. Ann Rheum Dis. 2005; Mar;64 Suppl 2:ii14-7.

7. ESPINOZA LR, CUELLAR ML: Psoriatic arthritis and spondylitis: a clinical approach. In Calin A, Taurog JD (editors). Spondyloarthritis. Oxford: Oxford University Press, 1998:97-111. 
8. GOLDENSTEIN-SCHAINBERG C., FAVARATO MMS, RANZA R., Conceitos atuais e relevantes sobre artrite psoriásica. Rev. Bras Reumatol. 2012;52(1):92106.

9. GOLDENSTEIN-SCHAINBERG C, SAAD CGS, GONÇALVES CR. Espondiloartrites. (In: Shinko SK). Reumatologia. São Paulo:Editora Atheneu, 2010; p. 137-53.

10. TAYLOR W, GLADMAN D, HELLIWELL P, MARCHESONI A, MEASE P, MIELANTS H; CASPAR STUDY GROUP: Classification criteria for psoriatic arthritis: development of a new criteria from a large international study. Arthritis Rheum. 2006; 54: 2665-73.

11. LIMA FR, GONÇALVES CR, GOLDENSTEIN-SCHAINBERG C. ESPONDILOARTROPATIAS. IN: YOSHINARI NH, BONFÁ ED (orgs). Reumatologia para o clinico. São Paulo: Roca, 2000; p. 111-22.

12. BOWCOCK AM, COOKSON WO. The genetics of psoriasis, psoriatic arthritis and atopic dermatites. Hum Mol Genet. 2004; 13:R43-55.

13. DUFFIN KC, CHANDRAN V, GLADMAN DD, KRUEGER GG, ELDER JT, RAHMAN P. Genetics of psoriasis and psoriatic arthritis: Update and future direction. J Rheumat. 2008; 35:1449-53.

14. NAIR RP, DUFFIN KC, HELMS C, DING J, STUART PE, GOLDGAR D et al. Genome-wide scan reveals association of psoriasis with IL-23 and NF-kappaB pathways. Nat Genet. 2009; 41:199-204. 
15. GLADMAN DD, ANHORN KA, SCHACHTER RK, MERVART H. HLA antigens in psoriatic arthritis. J Rheumatol. 1986 Jun; 13(3):586-92.

16. GONZALEZ S, MARTINEZ-BORRA J, TORRE-ALONSO JC, GONZALEZROCES S, SANCHEZ DEL RÍO J, RODRIGUEZ PÉREZ A, BRAUTBAR C, LÓPEZ-LARREA C. The MICA-A9 triplet repeat polyformphism in the trans membrane region confers additional susceptibility to the development of psoriatic arthritis and is independent of the association of $\mathrm{Cw}^{\star} 0602$ in psoriasis. Arthritis Rheum. 1999; May;42(5):1010-6.

17. HO PY, BARTON A, WORTHINGTON J, Plant D, Griffiths CE, Young HS, Bradburn P, Thomson W, Silman AJ, Bruce IN. Investigating the role of the HLA$\mathrm{Cw}^{\star} 06$ and HLA-DRB1 genes in susceptibility to psoriatic arthritis: comparison with psoriasis and undifferentiated inflammatory arthritis. Ann Rheum Dis. 2008; May;67(5):677-82. Epub 2007 Aug 29.

18. GLADMAN DD, FAREWELL VT, KOPCIUK KA, COOK RJ. HLA markers and progression in psoriatic arthritis.J Rheumatol. 1998; Apr;25(4):730-3.

19. BOMTEMPO CAS, LAGE RC, FERREIRA GAM, CARVALHO AP. Avaliação clínica, laboral e radiográfica de brasileiros com espondiloartropatias. Rev Bras Reumatol. v6; n4, p.238-245, jul/ago 2006.

20. BONFIGLIOLI R, CONDE A R, SAMPAIO-BARROS PD, LOUZADA-JUNIOR P, DONADI A E, BERTOLO BM. Frequency of HLA-B27 alleles in Brazilian patients with psoriatic arthritis. Clin Rheumat . 2008; 27:709-712. 
21. VASEY FB, DEITZ C, FENSKE NA, GERMAIN BF, ESPINOZA LR: Possible involvement of group A streptococci in the pathogenesis of psoriatic arthritis. $\mathbf{J}$ Rheumatol. 1982; 9: 719-22.

22. RANTAKOKKO K, RIMPILÄINEN M, UKSILA J, JANSÈN C, LUUKKAINEN R, TOIVANEN P:Antibodies to streptococcal cell wall in psoriatic arthritis and cutaneous psoriasis. Clin Exp Rheumatol. 1997; 15: 399-404.

23. ABBAS A K., LICHTMAN AH and PILLAI SHIV. Imunologia celular e molecular. 7ª̣ edição Elsevier 2011.

24. MEDZHITOV R, HURLBURT-PRESTON P, JANEWAY CA JR.: A human homologue of the Drosophila Toll protein signs activation of adaptive immunity. Nature. 1997; 388: 394-7.

25. KIYOSHI TAKEDA and SHIZUO AKIRA. Toll-like receptors in innate immunity. International immunology. 2005; vol 17, n1, p1-14.

26. KEOGH B, ANDREW E, PARKE A.E. Toll-like receptors as targets for immune disordes. Trens in Pharmacological Sciences. 2011; july; vol.32, n`7.

27. ROELOFS MF, ABDOLLAHI-ROODSAZ S, JOOSTEN LAB, VAN DEN BERG WB, RADSTAKE TRDJ: The orchestra of Toll-like receptor and their potential role in frequently occurring rheumatic conditions. Arthritis Rheum. 2008; 58: 338-48.

28. QING LIN, MINGCAI LI et al. The essential roles of toll-like receptor signaling pathways in sterile inflammatory diseases. International Immunopharmacology. 11 (2011) 1422-1432. 
29. TADEUCHI O, HOSHINO K, KAWAI T, et al. Differential roles of TLR2 and TLR4 in recognition of Gram-negative and Gram-positive bacterial cell wall components. Immunity. 1999; 11: 443-51.

30. SANTEGOETS, KCM., VAN BON, L. et al. Toll-like receptors in rheumatic diseases: Are we paying a high price for our defense against bugs. FEBS Letters 585 (2011) 3660-3666.

31. EVELYN A., KURT-JONES, LEISA MANDELL, CONSTANCE WHITNEY, ALISON PADGETT, KERRI GOSSELIN et al. Role of Toll-like receptor 2 (TLR2) in neutrophil activation: GM-CSF enhances TLR2 expression and TLR2-mediated interleukin 8 responses in neutrophis. Blood. 2002 vol.100, n.5;1860-

32. BOS, JD, DE RIE, MA, TEUNISSEM, MBM, PISKIN, G.. Psoriais: dyregulation of innate immunity. British journal of Dermatology. 2005; 152, pp1098-1107.

33. GARCIA-RODRIGUES, S. ARIAS-SANTIAGO, et al. Increased gene expression of Toll-Like receptor 4 on peripheral blook mononuclear cells in patients with psoriasis. JEADU (Journal of the European Academy of Dermatology an Venereology):2011.1-9.

34. BEGON E, MICHEL L, BEATRICE F et al:: Expression, subcellular localization and cytokinic modulation of Toll-like receptors (TLRs) in normal human keratinocytes: TLR2 up-regulation in psoriatic skin. Eur J Dermatol. 2007; 17: 497-506.

35. PAUKKONEN K, NAUKKARINEN A, HORSMANHEIMO M. The development of manifest psoriatic lesions is linked with the appearance of ICAM-1 positivity on keratinocytes. Arch Dermatol Res. 1995; 287(2):165-70. 
36. FITCH E, HARPER E, SKORCHEVA I, KURTZ SE, BLAUVEIT A. Pathophysiology of psoriasis: recente advances on IL-23 and $\mathrm{TH} 17$ cytokines. Curr Rheumatol Rep. 2007; 9:461-7.

37. CANDIA L, MARQUEZ J, HERNANDEZ C, ZEA AH, ESPINOZA LR: Toll-like receptor-2 expression is upregulated in antigen-presenting cells from patients with psoriatic arthritis: a pathogenic role for innate immunity? J Rheumatol. 2007; 34: 364-9.

38. PREVOO MLL, VAN'T HOFF MA, KUPER HH, VAN LEEUWEN MA, VAN DE PUTTE LBA, VAN RIEL PLCM: Modified disease activity scores that include twenty-eight-joint counts. Development and validation in a prospective and longitudinal study of patients with rheumatoid arthritis. Arthritis Rheum. 1995; 38: 44-8.

39. MARTI GE, STELER-STEVENSON M, BLEESING JJH, FLEISHER TA. Introduction to Flow Cytometry. Sem Hematol. 2001;38(2):93-9.

40. BACAL NS, FAULHABER MHW. Introdução a citometria de fluxo. In: Aplicação prática em citometria de fluxo. São Paulo, Editora Atheneu, 2003. Cap1, p1-4.

41. PEREIRA J. Estudo de células percursoras em leucemias agudas: Identificação e fator de prognóstico das proteínas BCL-2, Bax e CD95?Fas/APO-1. [Tese]. São Paulo: Faculdade de Medicina, Universidade de São Paulo; 2000.

42. IWAHASHI M, YAMAMURA M, AITA T et al.: Expression of Toll-like receptor 2 on CD16+ blood monocytes and synovial tissue macrophages in rheumatoid arthritis. ArthritisRheum. 2002; 46: 298-308. 
43. YAVUZ S, ELBIR Y, TULUNAY A, EKSIOGLUDEMIRALP E, DIRESKENELI H: Differential expression of toll-like receptor 6 on granulocytes and monocytes implicates the role of microorganisms in Behçet's disease etiopathogenesis. Rheumatol Int. 2008; 28: 401-6.

44. ChIMENTI, MS, BAllanti, E., PERRICONE, C., CIRPIANI, P., GIACOMELLI, R., PERRICONE, R. Immunomodulation in psoriatic arthritis: Focus on cellular and molecular pathways. Autoimmunity reviews. 2013 v12, 599-606.

45. TOICHI E, TACHIBANA T, FURUKAWA F. Rapid improvement of psoriasis vulgaris during drug-induced agranunocytosis. J. Am. Acad Dermatol. 2000 Aug;43 (2 Pt 1):391-5.

46. KRUITHOF, E., BAETEN, D., DE RYCKE, L. et al.Synovial histopathology of psoriatic arthritis, both oligo- and polyarticular, resembles spondyloarthropathy more than it does rheumatoid arthritis. Arthritis research \& terapy, vol7 n3, 2005.

47. BAKER, BS, OVIGNE, JM, POWLES, AV, CORCORAN, S, FRY, L: Normal keratinocytes express Toll-like receptors (TLRs) 1, 2 and 5: modulation of TLR expression in chronic plaque psoriasis. Br J Dermatol. 2003; 148: 670-9.

48. DE RYCKE L, VANDOOREN B, KRUITHOF E, DE KEYSER F, VEYS EM, BAETEN D: Tumor necrosis factor a blockade treatment down modulates the increased systemic and local expression of Toll-like receptor 2 and toll-like receptor 4 in spondylarthropathy. Arthritis Rheum. 2005; 52: 2146-58.

49. EKMAN P, KIRVESKARI J, GRANFORS K: Modification of disease outcome in Salmonella-infected patients by HLA-B27. Arthritis Rheum. 2000; 43: 1527-34. 
50. TAUROG JD, RICHARDSON JA, CROFT JT et al:: The germfree state prevents development of gut and joint inflammatory disease in HLA-B27 transgenic rats. $\mathbf{J}$ Exp Med. 1994; 180: 2359-64.

51. BAETEN D, DE KEYSER F, VEYS E, MIELANTS H: Immune linkages between inflammatory bowel disease and spondyloarthropathies. Curr Opin Rheumatol. $2002 ; 14: 342-7$.

52. DE KEYSER F, ELEWAUT D, DE VOS M et al:: Bowel inflammation and the spondyloarthropathies. Rheum Dis Clin North Am. 1998; 24: 785-813.

53. GOMES, FR. Expressão do fator estimulador de colônia de granulócito humano recombinante (rhG-CSF) em Eschirichia coli. [Tese] apresentada pelo Instituto Butantã. São Paulo 2010.

54. WElte, K., GABRILOVE, J., BRONCHUD, MH, PLATZER, E., MARSTYN, G. Filgrastin (r-metHuG-CSF): The first 10 years. Blood. 1996 v.88, n6 pp19071929.

55. VASQUEZ-TORRES A, JONES-CARSON J, BÃUMLER AJ, FALKOW S, VALDIVIA R, BROWN W, et al. Extraintestinal dissemination of Salmonella by CD-18-expressing phagocytes. Nature. 1999;401:804-8.

56. HÃUPL T, HAHN G, RITTIG M, KRAUSE A, SCHOERNER C, SCHÖNHERR U, et al. Persistence of Borrelia burgdorferi in ligamentous tissue from a patient with chronic Lyme borreliosis. Arthritis Rheum. 1993;36:1621-6. 
APÊNDICE 


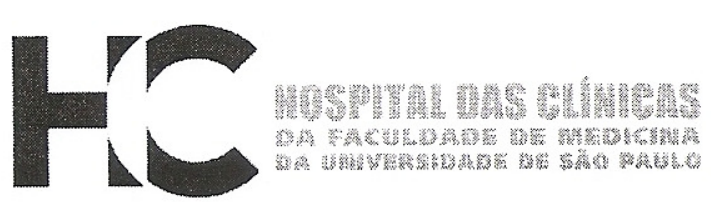

\section{APROVAÇÃO}

A Comissão de Ética para Análise de Projetos de Pesquisa - CAPPesq da Diretoria Clínica do Hospital das Clínicas e da Faculdade de Medicina da Universidade de São Paulo, em sessão de 01/08/2007, APROVOU o Protocolo de Pesquisa n 0533/07, intitulado: "EXPRESSÃO DE RECEPTORES TOLL-LIKE (TOLL-LIKE RECEPTORS) 2 E 4 EM MONÓCITOS E GRANULÓCITOS DO SANGUE PERIFÉRICO EM PACIENTES PORTADORES DE ARTRITE REATIVA E ARTRITE PSORIÁSICA" apresentado pelo DEPARTAMENTO DE CLÍNICA MÉDICA, inclusive o Termo de Consentimento Livre e Esclarecido.

Cabe ao pesquisador elaborar e apresentar à CAPPesq, os relatórios parciais e final sobre a pesquisa (Resolução do Conselho Nacional de Saúde $n^{\circ}$ 196, de 10/10/1996, inciso IX.2, letra "c").

Pesquisador (a) Responsável: Cláudia Goldenstein Schainberg Pesquisador (a) Executante: Fabricio de Souza Neves

CAPPesq, 07 de Agosto de 2007

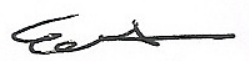

Prof. Dr. Eduardo Massad Presidente da Comissão de Ética para Análise de Projetos de Pesquisa

Comissão de Ética para Análise de Projetos de Pesquisa do HCFMUSP e da FMUSP Diretoria Clínica do Hospital das Clínicas da Faculdade de Medicina da Universidade de São Paulo Rua Ovídio Pires de Campos, 255, 5ªndar - CEP 05403010 - São Paulo - SP Fone: 01130696442 Fax: 01130696492 e-mail: cappesq@hcnet.usp.br / secretariacappesq2@hcnet.usp.br - fe 
Hospital das Clínicas da FMUSP

Comissăo de Ética para Análise de Projetos de Pesquisa

CAPPesq

Ao

Departamento de Clínica Médica

O Coordenador da Comissāo de Ética para Análise de Projetos de Pesquisa-CAPPesq da Diretoria Clínica do Hospital das Clínicas da Faculdade de Medicina da Universidade de Sāo Paulo, em 30.08.11 tomou conhecimento que o Protocolo de Pesquisa $n^{\circ}$ 0533/07 intitulado "EXPRESSÃO DE RECEPTORES TOLL-LIKE (TOLL-LIKE RECEPTORES) 2 E 4 EM MONÓCITOS E GRANULÓCITOS dO SANGUE PERIFÉRICO EM PACIENTES PORTADORES DE ARTRITE REATIVA E ARTRITE PSORIÁSICA", qUe tem como pesquisadora responsável a Profa. Dra. Cláudia Goldenstein Schainberg, será dissertação de mestrado da aluna SOLANGE CARRASCO, tendo como orientadora a PROFA. DRA. SUZANA BEATRIZ VERÍSSIMO DE MELLO.

CAPPesq, 30 de agosto de 2011.

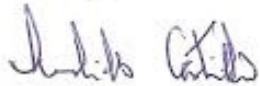

PROF. DR. EUCLIDES AYRES DE CASTILHO

Coordenador

Comissão de Ética para Análise de Projetos de Pesquisa - CAPPesq 


\section{HOSPITAL DAS CLÍNICAS}

DA FACULDADE DE MEDICINA DA UNIVERSIDADE DE SÃo PAULO

CAIXA POSTAL, 8091 - SÃO PAULO - BRASIL

TERMO DE CONSENTIMENTO LIVRE E ESCLARECIDO

\section{I - DADOS DE IDENTIFICAÇÃO DO SUJEITO DA PESQUISA OU RESPONSÁVEL LEGAL}

1. NOME DO PACIENTE

DOCUMENTO DE IDENTIDADE No:

SEXO: M F

DATA NASCIMENTO: ........................

ENDEREÇO

. No

No ……................... APTO:

BAIRRO: CIDADE

CEP:.

TELEFONE: DDD ( ..)

2.RESPONSÁVEL LEGAL

NATUREZA (grau de parentesco, tutor, curador etc.)

DOCUMENTO DE IDENTIDADE :

SEXO: $M \quad F$

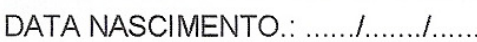

ENDEREÇO:

$N^{0}$

APTO:

BAIRRO:

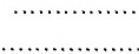

CEP

TELEFONE: DDD (

CIDADE:

\section{II - DADOS SOBRE A PESQUISA CIENTÍFICA}

1. TÍTULO DO PROTOCOLO DE PESQUISA: EXPRESSÃO DE RECEPTORES TOLL-LIKE (TOLL-LIKE RECEPTORS) 2 E 4 EM MONóCITOS E GRANULÓCITOS DO SANGUE PERIFÉRICO EM PACIENTES PORTADORES DE ARTRITE REATIVA E ARTRITE PSORIÁSICA

PESQUISADOR: Dra. Cáudia Goldenstein Schainberg.

CARGO/FUNÇÃO: ...Médica. INSCRIÇÃO CONSELHO REGIONAL No 52963

UNIDADE DO HCFMUSP: Departamento de Reumatologia.

3. AVALIAÇÃO DO RISCO DA PESQUISA:

$\begin{array}{ll}\text { SEM RISCO } & \text { RISCO MÍNIMO X RISCO MÉDIO } \\ \text { RISCO BAIXO } & \text { RISCO MAIOR }\end{array}$

(probabilidade de que o indivíduo sofra algum dano como consequência imediata ou tardia do estudo)

4.DURAÇÃO DA PESQUISA :...2 anos. 


\section{Justificativa e os objetivos da pesquisa}

A Artrite Reativa (ARe) e Artrite Psoriásica (APs)l são doenças articulares inflamatórias crônicas que fazem parte do grupo das Espondiloartropatias e compartilham características comuns, como associação com o HLA B27. O papel de agentes infecciosos como fator desencadeante nestas doenças tem sido especulado. Enquanto que relação entre bactérias Gram-negativas entéricas é comum na $\mathrm{ARe}, 0$ envolvimento infeccioso nas demais entidades do grupo não é claramente estabelecido. Na APS, é possível que bactérias Gram-positivas, colonizadoras de lesões cutâneas, participem da sua patogenia. Os Receptores Toll-like (Toll-like Receptors, TLR) foram recentemente descritos como capazes de reconhecer padrões moleculares associados a patógenos e ativar a resposta imune inata, de modo que o TLR-2 reconhece germes Gram-positivos enquanto que o TLR-4 reconhece Gram-negativos. Portanto, avaliaremos neste estudo a expressão de TLR-2 e TLR-4 em monócitos e granulócitos de pacientes portadores de ARe e APs.

2. Procedimentos que serão utilizados e propósitos, incluindo a identificação dos procedimentos que são experimentais

No dia de sua consulta normal no ambulatório de Reumatologia você será entrevistado pelo médico pesquisador, que fará perguntas a respeito dos sintomas e sinais que podem ocorrer na Artrite reativa e na Artrite Psoriásica.

Uma pequena quantidade $(2 \mathrm{ml})$ de sangue será retirado da veia do braço, com uma agulha fina, da mesma maneira como é normalmente colhido sangue para seus exames de controle habituais. Esse sangue será levado pelo médico pesquisador ao laboratório, onde as células do sangue serão separadas e, usando um aparelho chamado Citômetro, será possível contar células com receptores "Toll" circulantes no seu sangue.

Os exames de sangue e urina serão solicitados e colhidos no laboratório do Hospital das Clínicas da mesma maneira que nas consultas habituais.

3. Desconfortos e riscos esperados

\section{O desconforto/risco desta pesquisa é representado pelos seguintes fatores:}

- Ter que ir para o hospital para a consulta médica;

- Ter de responder ao questionário sobre a doença (duração estimada de dez minutos);

- Colher sangue para os testes. Para colher sangue é puncionada uma veia com agulha, por isso pode ser sentida uma leve dor no local ou a formação de uma equimose ("roxo"), que desaparece em pouco tempo;

- Passar pelo Laboratório Central do HC para coleta de sangue para exames de rotina;

4. Benefícios que poderão ser obtidos

Esclarecemos que a participação neste estudo não trará nenhum benefício direto. Não será cobrado nem será fornecida remuneração em dinheiro ou outra vantagem financeira pela participação neste estudo. 
Contudo, os resultados deste estudo, podem, em longo prazo, oferecer vantagens para as pessoas com Artrites, possibilitando um melhor diagnóstico e um tratamento mais adequado.

Seu tratamento não será modificado pelos pesquisadores, pois você continuará sendo acompanhado pelo médico que normalmente o assiste, o qual acompanhará os trabalhos deste estudo.

5. Procedimentos alternativos que possam ser vantajosos para o indivíduo

Terá a oportunidade, se desejar, de marcar outras consultas com a equipe para esclarecimento de eventuais dúvidas ou questões a discutir, refletir e pensar junto ao profissional responsável pela pesquisa.

\section{IV - ESCLARECIMENTOS DADOS PELO PESQUISADOR SOBRE GARANTIAS DO SUJEITO DA PESQUISA CONSIGNANDO:}

1. Você poderá ter acesso, quando desejar, às informações sobre procedimentos, riscos e benefícios relacionados à pesquisa, inclusive para esclarecer eventuais dúvidas.

2. Você continua livre para retirar seu consentimento a qualquer momento e deixar de participar do estudo, sem que isto traga prejuízo à continuidade da assistência.

3. As informações pessoais obtidas nas entrevistas não serão divulgadas em público, sendo assegurada a salvaguarda da confidencialidade, sigilo e privacidade.

4. Fica assegurado a você a disponibilidade de assistência no HCFMUSP através do Serviço/Disciplina de Reumatologia, por eventuais danos à saúde, decorrentes da pesquisa.

5. No cumprimento do item anterior, não cabe indenização.

\section{INFORMAÇÕES DE NOMES, ENDEREÇOS E TELEFONES DOS RESPONSÁVEIS PELO ACOMPANHAMENTO DA PESQUISA, PARA CONTATO EM CASO DE INTERCORRÊNCIAS CLÍNICAS E REAÇÕES ADVERSAS.}

Fabrício de Souza Neves, médico, Pós-Graduando em Ciências Médicas da FMUSP, registrado no Conselho Federal de Medicina de São Paulo sob o numero 113.771; enderço à Av. Dr. Altino Arantes 742 , ap 84, São Paulo - SP, fone 8243-7584. 
Pode ser também contactado no ambulatório de Reumatologia do Hospital das Clínicas: Av. Dr. Enéas de Carvalho Aguiar, 255, CEP 05403-900 - SP - Brasil Telefone: (11) 3069-6384 (ambulatório)

\section{OBSERVAÇÕES COMPLEMENTARES:}

Você será mantido informado sobre os resultados parciais da pesquisa sempre que assim o desejar e solicitar, bem como será informado sobre outros conhecimentos que possam influenciar na minha decisão de continuar na pesquisa.

Em seus comparecimentos, você receberá se assim desejar um atestado médico comprovando sua participação no estudo.

\section{VII - CONSENTIMENTO PÓS-ESCLARECIDO}

Declaro que, após convenientemente esclarecido pelo pesquisador e ter entendido o que me foi explicado, consinto em participar do presente Protocolo de Pesquisa

São Paulo, de de 2011 


\section{Toll-like receptor (TLR) 2 is upregulated on peripheral blood monocytes of patients with psoriatic arthritis: a role for a gram-positive inflammatory trigger?}

S. Carrasco, F.S. Neves, M.H. Fonseca, C.R. Gonçalves, C.G. Saad, P.D. Sampaio-Barros, C. Goldenstein-Schainberg

Rheumatology Division, University of Sao Paulo (USP), Brazil.

\begin{tabular}{|c|}
\hline $\begin{array}{l}\text { Abstract } \\
\text { Toll-like receptor (TLR) } 2 \text { and TLR4 are able to activate innate immune cells in response to gram-positive and gram- } \\
\text { negative bacteria, respectively. Psoriatic arthritis }(P s A) \text { is a chronic inflammatory joint disease and gram-positive } \\
\text { streptococcus may have a role in its pathogenesis, suggesting the importance of TLR2 stimulation in PsA. }\end{array}$ \\
\hline s TLR2 and TLR4 expressions on innate immu \\
\hline $\begin{array}{l}\text { Methods } \\
\text { Forty-five patients with peripheral joint manifestations of PsA were included and disease activity was assessed by Disease } \\
\text { Activity Score of } 28 \text { joint counts (DAS28). } 32 \text { healthy subjects constituted the control group. Membrane-bound TLR } 2 \text { and } \\
\text { TLR4 expressions were assessed on peripheral blood monocytes and neutrophils by flow cytometry. }\end{array}$ \\
\hline $\begin{array}{c}\text { Results } \\
\text { Twenty-seven patients had active PSA (DAS28 higher than 2.6) and } 18 \text { had inactive disease. TLR2 was significantly } \\
\text { upregulated on monocytes in both active and inactive PSA group, comparing to healthy controls. TLR4 was similarly } \\
\text { expressed in all tested groups. }\end{array}$ \\
\hline $\begin{array}{l}\text { Conclusion } \\
\text { is overexpressed by PsA monocytes, suggesting that gram-positive exposure could induce higher inflammatory } \\
\text { responses in this disease. }\end{array}$ \\
\hline
\end{tabular}

Key words

psoriatic arthritis, toll-like receptors, innate immunity, monocytes, neutrophils 


\section{Toll-ike receptor $\mathbf{2}$ in psoriatic arthritis / S. Carrasco et al.}

Solange Carrasco, BSC

Fabricio S. Neves, MD, PhD

Marcela $H$. Fonseca, PhD

Célio R. Gonçalves, $M D, P h D$

Carla G. Saad, MD

Percival D. Sampaio-Barros, $M D, P h D$

Cláudia Goldenstein-Schainberg, MD, PhD

Please address correspondence to:

Dr Fabricio Souza Neves.

Reumatologia

Faculdade de Medicina da

Universidade de São Paulo,

Av. Dr. Arnaldo, $455,3^{\circ}$ andar, sala 3133 ,

Pacaembu, São Paulo,

SP. CEP 01246-903, Brazil.

E-mail:nevesfds@gmail.com

Reprints will not be available from the author.

Received on February 28, 2011; accepted in revised form on May 20, 2011.

(c) Copyright CLINICAL AND

EXPERIMENTAL RHEUMATOLOGY 2011

Funding: The Fundação de Amparo a Pesquisa do Estado de São Paulo (FAPESP, protocol number 2007/58625-5). provided financial and material support. Competing interests: none declared.

\section{Introduction}

Spondyloartritis $(\mathrm{SpA})$ are a group of chronic inflammatory diseases characterised by axial and peripheral arthritis and enthesitis in close association with HLA-B27 (1). Its pathogenesis remains largely unclear, but an important clue is provided by the relation of environmental triggers and genetic background. In reactive arthritis, a subtype of $\mathrm{SpA}$. chronic disease is clearly triggered by a precedent gastrointestinal or urogenital bacterial infection (2), and germ-free state prevents the development of $\mathrm{SpA}$ features in the HLA-B27 transgenic rat model (3). It is proposed that microbial products are presented to CD8+ lymphocytes in the context of HLA-B27+ antigen-presenting cells, initiating the inflammatory response (4).

Additionally, besides $T$ cell antigen recognition, human innate immune cells may act in direct response to bacterial components through a system that primarily comprises Toll-like receptors (TLR) (5). TLR2 and TLR4 are extracellular receptors that recognise respectively, gram-positive and gramnegative bacterial lipid-based structures (lipoteichoic acid and lypolysaccharide, in that order) (6). Toll-like receptor activation on monocytes and neutrophils ultimately results in cellular activation and production of several stimulating cytokines $(7,8)$, which would contribute to the development and maintenance of the pro-inflammatory background of some chronic inflammatory diseases.

Psoriatic arthritis (PsA) is a subtype of $\mathrm{SpA}$ and there is subtle evidence of its link to gram-positive bacteria exposure Vasey et al. proposed that, if some bacteria are important in triggering PsA they may be those comprising skin flora, and found that levels of antibodies against streptococcal exotoxin are higher in patients with PsA comparing to healthy controls and patients with rheumatoid arthritis (9). These findings were further confinmed: higher levels of antibodies to different streptococcal cell wall components were also found in patients with $\mathrm{PSA}_{\mathrm{S}}$ and cutaneous psoriasis (10). Regarding innate immune stimulation by bacterial components, it was observed that TLR2 expression is upregulated in psoriatic skin lesions(11). TLR2 was also found to be overexpressed on immature dendritic cells obtained from patients with active PSA (12). Thus, it has been hypothesized that inappropriate gram-positive overstimulation on the innate immune system may have a role on PsA pathogenesis. To reaffirm this hypothesis and correlate these findings with disease activity, we intended to assess the expressions of TLR2 and TLR4 on peripheral blood monocytes and neutrophils from patients with active and inactive PsA comparing to healthy controls.

\section{Methods}

\section{Patients and controls}

Our study group included PSA patients who were followed at the SpA outpatient clinic at the Rheumatology Division of the Hospital das Clinicas, the teaching hospital of the University of Sao Paulo, Brazil. All patients met CASPAR criteria for the diagnosis of PsA (13). Only patients with peripheral disease were included (RA-like, asymmetric oligoarthritis, distal interphalangeal arthritis or destructive arthritis). Patients with isolated axial disease were not included. The Disease Activity Score of 28 joint counts (DAS28) was used to assess clinical disease activity $(14,15)$. Active PsA was considered when DAS28 value was higher than 2.6. Demographic and medication data were also recorded. Healthy volunteers recruited from laboratory and hospital staffs were included as a control group. Our study design was consistent with the principles of the Declaration of Helsinki and received institutional ethics committee approval (CAPPesq, protocol number 0533/07). Written informed consent was obtained from all subjects prior to study commencement.

Assessment of membrane-bound expressions of TLR2 and TLR4

Venous blood samples were taken from PsA patients and normal controls in EDTA tubes. Two hundred microlitres of each sample was placed in tubes containing $2 \mathrm{ml}$ of $0.1 \%$ azide in phosphatebuffered saline (PBS), centrifuged at $2000 \mathrm{rpm}$ for 3 minutes and mixed with $50 \mu \mathrm{l}$ of $2 \%$ foetal calf serum (FCS) and 


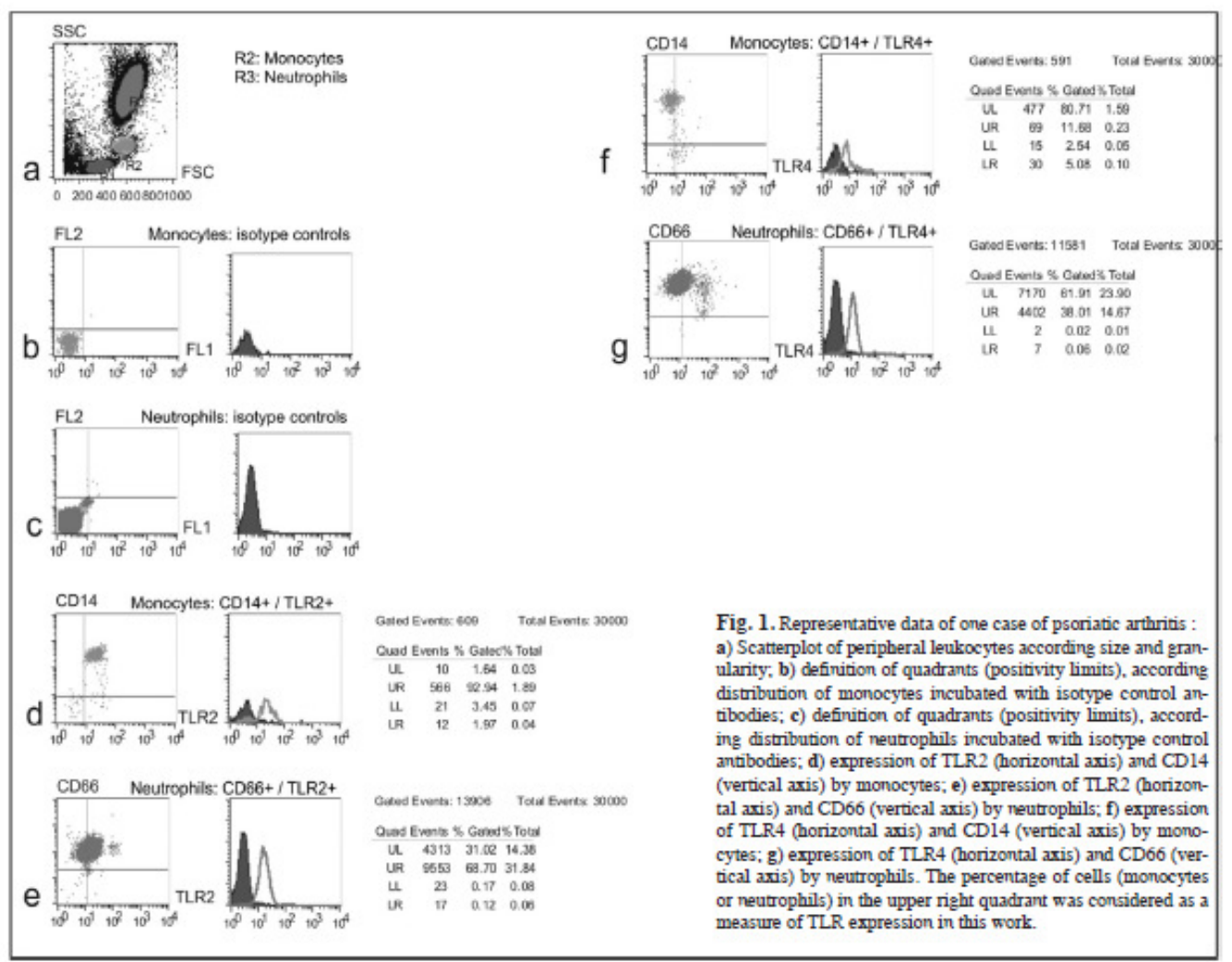

$0.1 \%$ azide-PBS. Afterwards, cell samples were incubated for 20 minutes with unconjugated anti-human Fc Receptor (FcR Block Reagent, eBioscience, San Diego, CA, USA) to avoid subsequent unspecific adhesion of labelled monoclonal antibodies $(\mathrm{mAb})$ to $\mathrm{Fc}$ receptors on innate immune cells. Following the manufacturer's instructions (BD Biosciences, San Jose, CA, USA), cells were stained with the following $\mathrm{mAbs}$ : phycoerythrin $(\mathrm{PE})$ conjugated mouse anti-human CD66 mAb, as a specific marker of PMN (FL2), PerCP-Cy5.5 conjugated mouse anti-human CDl4 $\mathrm{mAb}$ (FL3) and Alexa-Fluors conjugated mouse anti-human TLR2, biotinylated mouse anti-human TLR4 mAb (added to streptavidin labelled with fluorescein isothiocyanate - FITC) and FTTC conjugated mouse anti-human CDIl6 mAb (FLl) or isotype control antibody for 20 minutes. FITC con- jugated anti-human CD66 (FLl) was used as a PMN marker with PE conjugated mouse anti-human CD114 (FL2). Erythrocytes were lysed with appropriated lysing solution (BD Biosciences), and stained cells were washed twice in $0.1 \%$ azide-PBS solution and fixed in $1 \%$ paraphormaldeyde prior to flow cytometric analysis. Ten thousand cells from each sample were then analysed in a three-fluorescence detector FACScalibur ${ }^{\text {nx }}$ device with CellQuest ${ }^{\mathrm{TM}}$ software (BD Biosciences). PMN and monocyte regions were gated in the forward scatter/side scatter chart. In each specific region, PMNs and monocytes were defined as $\mathrm{CD} 66+$ or $\mathrm{CDl} 4$ + cells, respectively. After that, the percentage of cells expressing TLR2 or TLR4 was counted, as the number of cells in the upper right quadrant. Positivity limits for dot plot chats were defined using isotype antibody controls. Representa- tive data of one case are presented in Figure 1.

Statistical analysis

All analyses were performed with the SPSS 15.0 for Windows ${ }^{\star}$ (SPSS, Chicago, IL, USA) statistical software package. Comparisons between groups were carried out using the Mann-Whitney Utest and results are expressed as median \pm interquartile range, consistent with a non-parametric distribution as assessed by the Shapiro-Wilk test. $P$-values under 0.05 were considered significant.

\section{Results}

Forty-five patients with PsA (22 women, 23 men, mean age $52 \pm 13$ years, mean disease duration $15 \pm 10$ years) were included. Twenty-seven patients were considered with active disease (mean DAS 28 score 3.75 ) and 18 patients had inactive PsA (mean DAS 28 score 1.76). Four patients with active 
Toll-like receptor 2 in psoriatic arthritis / S. Carrasco et al.

Table I. Expressions of TLR2 and TLR4 by circulating monocytes and neutrophils from patients with PsA, active PsA, inactive PsA and controls.

\begin{tabular}{|c|c|c|c|c|}
\hline & \multicolumn{2}{|c|}{ TLR 2} & \multicolumn{2}{|c|}{ TLR 4} \\
\hline & Monocytes (\%) & Neutrophils (\%) & Monocytes (\%) & Neutrophils (\%) \\
\hline Ps.A vs. controls & $\begin{array}{c}89 \pm 17 \text { vs. } 71 \pm 49 \\
p=0.002^{*}\end{array}$ & $\begin{array}{c}6 \pm 29 \text { vs. } 18 \\
p=0.07\end{array}$ & $\begin{array}{c}2 \pm 9 \text { vs. } 1 \pm 3 \\
p=0.23\end{array}$ & $\begin{array}{c}2 \pm 9 \text { vs. } 1 \pm 3 \\
p=0.48\end{array}$ \\
\hline Active $P_{5} A$ vs. controls & $\begin{array}{c}90 \pm 17 \text { vs. } 71 \pm 49 \\
p=0.001^{*}\end{array}$ & $\begin{array}{c}5 \pm 39 \text { vs. } 18 \pm 31 \\
p=0.15\end{array}$ & $\begin{array}{c}2 \pm 4 \text { vs. } 1 \pm 3 \\
p=0.33\end{array}$ & $\begin{array}{c}2 \pm 7 \text { vs. } 1 \pm 3 \\
p=0.69\end{array}$ \\
\hline Inactive $P_{s} A$ vs. controls & 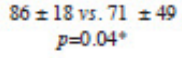 & $\begin{array}{c}8 \pm 24 \text { vs. } 18,50=31 \\
p=0.10\end{array}$ & $\begin{array}{c}2 \pm 15 \text { vs. } 1 \pm 3 \\
p=0.29\end{array}$ & $\begin{array}{c}2 \pm 11 \text { vs. } 1 \pm 3 \\
p=0.42\end{array}$ \\
\hline Active $P_{5} A$ vs. iractive $P_{5} A$ & $\begin{array}{c}90 \pm 17 \text { vs. } 86 \pm 18 \\
p=0.10\end{array}$ & $\begin{array}{c}5 \pm 39 \text { vs. } 8 \pm 24 \\
p=0.74\end{array}$ & $\begin{array}{c}2 \pm 4 \text { vs. } 2=15 \\
p=0.83\end{array}$ & $\begin{array}{c}2 \pm 7 v s .2 \pm 11 \\
p=0.66\end{array}$ \\
\hline
\end{tabular}

PSA and two patients with inactive PsA were in use of anti-TNF- $\alpha$ agents. Only one patient was in remission state without medication and the others were in use of traditional diseasemodifying anti-rheumatic drugs, some of them in combination (DMARDs) and non-steroidal anti-inflammatory drugs (NSAIDs): 23 on methotrexate (15 active and 8 inactive PsA), 4 on sulphasalazine ( 3 active and 1 inactive PsA), three on leflunomide (all active PSA) and one on cyclosporine (active PsA). Three patients with active PsA and five patients with inactive PsA were in use of NSAIDs without DMARDs. Thirty-two healthy subjects were included as a control group.

Table I demonstrates the expression of TLR2 and TLR4 on peripheral monocytes and neutrophils from PSA patients and controls. Expression levels of TLR2 was significantly higher on monocytes from PsA patients than on monocytes from healthy controls $(89 \% \pm 17 \%$ vs. $71 \% \pm 49 \%, p=0.002$ ). Both active PsA $(90 \% \pm 17 \%$ vs. $71 \% \pm 49 \%, p=0.001)$ and inactive PsA patients $(86 \% \pm 18 \%$ vs. $71 \% \pm 49 \%, p=0.004)$ revealed higher TLR2 expression on monocytes than controls. There was no significant difference between active and inactive PsA groups regarding TLR2 expression on circulating monocytes.

In contrast TLR4 was similarly expressed on monocytes of all groups of patients and controls. Furthermore on neutrophils, both TLR2 and TLR4 were similarly expressed in patients and controls. All data are presented in Table I.

\section{Discussion}

Promising recent reports point out to the potential role for TLRs in a variety of inflammatory disorders (16-18). Studies in psoriasis have shown that normal epidermal keratinocytes constitutively express TLR2 (19), while psoriatic skin lesions overexpress this receptor in comparison to normal skin (11). Because gram-positive bacteria such as streptococcus may have a relevant role in inducing $\mathrm{P}_{\mathrm{S}} \mathrm{A}(9,10)$, skin overexpression of TLR2 may be involved in the mechanism linking bacterial exposure and cutaneous inflammation in this disease.

In PsA, Candia et al. (12) reported that TLR2 expression (but not TLR4) was upregulated in immature dendritic cells obtained on cultured monocytes from active PsA patients, thus suggesting that gram-positive bacterial triggering and TLR2 overexpression also specifically contribute to the imunopathogenic process involved in joint disease related to psoriasis. On the other hand, in ankylosing spondilitis (AS, the prototype form of $\mathrm{SpA}$ ) both TLR2 and TLR4 were found to be upregulated in peripheral blood monocytes (20). Thus, one can suggest that while PsA inflammation is specifically exacerbated by gram-positive stimulation via TLR2, AS inflammation may be boosted by gram-negative stimulation through TLR4. This hypothesis makes sense considering the cutaneous source of bacterial stimulation in psoriasis, mainly gram-positive ( 9 ), while in AS gut inflammation and increased gut permeability to gram-negative intesti- nal flora may play a role in its pathogenesis (21)

Our results give additional support to this hypothesis, revealing that only TLR2 is upregulated on circulating monocytes of PsA patients irrespective of disease activity status. This could provide a preferential gram-positive overstimulation in PsA, which would lead to inflammatory activation. Probably Candia et al. (12) did not observe TLR2 overexpression in circulating monocytes (but only in immature dendritic cells) due to the small number of patients evaluated (only ten patients were considered in their study.

Our data and those from Candia et al. suggest that TLR2 overexpression in PsA may be a preferential route for bacterial triggering of the innate immune system (12). Reinforcing this idea, De Rycke et al. observed that anti-TNF- $\alpha$ blockade sharply abolishes TLR 2 and TLR4 hyperexpression in AS patients (20). It suggests that TLR overexpression may have in fact a role in the inflammatory responses observed in these diseases. In our study, anti-TNF- $\alpha$ agents were similarly used in 4/27 active and 2/18 inactive PSA patients and did not influence our results.

In conclusion, the demonstration of TLR2 overexpression on circulating monocytes from patients with PsA may suggest a role of gram positive microroganisms triggering inflammatory responses in this disease. Functional studies are clearly warranted to clarify the pathological significance of TLR stimulation in PsA. 
References

1. MOLI NM, HASLOCK I, MACRAE IF, WRIGHT $\mathrm{V}:$ Associations between ankylosing spondilitis, psoriatic arthritis, Reiter 's disease, the intestinal arthropaties, and Bebçet's syndrome Medicine (Baltimore) 1974; 53: 343-64

2. ERMAN $P$, KIIKVESKARI J, GRANFORS $E$ : Modification of disease outcome in SalmonModa-infected pacients by HLA-B27. Anthritis Rhewem 2000; 43 : 1527-34

3. TAUROG RD, RICHARDSON JA, CROFT IT C

al.: The germifee state prevents development of gut and joint inflammatory disease in HL_A-B27 transgenic rats. J Exp Med 1994, 180: 2359-64.

4. BAETEND, DE KEYSER F, VEYS E, MIELANTS H: Immune linkages between inflammatory bowel disease and spondyloarthropathies. Curr Opin Rheumatol 2002; 14 : $342-7$.

5. MEDZHITOV R, HURL BURT-PRESTON P. JANEWAY CA JR: A human homologue of the Drosophila Toll protein signs activation of Drosophila Toll protein signs activation of
adaptive immunity. Nature 1997; $388: 3947$. adaptive immunity. Nature 1997: $388: 394-7$.
6. ROEIOFS MF, ABDOLLAHI-ROODSAZ S, 6. ROELOFS MF, ABDOLLAHI-ROODSAZ S,
JOOSTENLAB, VANDENBERG WB,RADSTAKE TRDJ: The orchestra of Toll-like receptor and their potential role in frequently occurring rheumatic conditions. Arthritis Rheum 2008, 58: $338-48$.

7. LOTZ S, AGA E, WILDE I et al: Highly purifed lipoteichoic acid activates neutrophil granulocytes and delays their spontaneous apoptosis via CD 14

8. SCFRODDER NWJ, MORATH S,ALEXANDER C et al : Lipoteichoic Acid (LTA) of streptococcus pneumoniae and staphylococcus aureus activates immune cells via toll-like receptor (TLR)-2, lypopolysaccharide-binding pro- tein (LBP), and CD14, whereas TLR-4 and MD-2 are not involved. $J$ Biol Chem 2003 . 278: 15587-94.

9. VASEY FB, DEITZ C, FENSIEE NA, GERMAD BF, ESPINOZA LR: Possible involvement of group A streptococci in the pathogenesis of psoriatic arthritis. I Rhewmatol 1982; 9: 719 22.

10. RANTAKOKKO $\mathrm{K}$, RTMPILÄNEN M, UKSILA J, JANSEN C, LUUKKAINEN $R$, TORVANEN P: Antibodies to streptococcal cell wall in psoriatic arthritis and cutaneous psoriasis. Clin riatic arthritis and cutaneous psoniasis.
Exp Rhewmatol 1997; 15: 399-404.

11. BEGON E, MICHEL L, BEATRICE F et al: Expression, subcellular localization and cytokinic modulation of Toll-like receptors (TLRs) in normal human keratinocytes: TLR2 up-regulation in psoriatic skin. Ew $J$ Dermatol 2007; 17: 497-506.

12. CANDIA I, MARQUEZ J, HERNANDEZ C ZEA AH, ESPDNOZA LR: Toll-like receptor-2 expression is upregulated in antigen-present-
ing cells from patients with psoriatic arthritis: a pathogenic role for imuate immunity? $J$ Rheumatol 2007; 34: 364-9.

3. TAYLOR W, GLADMAN D, HELLWELI P. MARCHESONI A, MEASE $P$, MIELANTS H; CASPAR STUDY GrotP: Clssification criteria for psoriatic arthritis: development of a new criteria from a large international study. Arthritis Rheum 2006; 54: 2665-73.

14. PREVOO MLI, VAN'T HOFF MA, KUPER HH, VAN LFEUWEN MA, VAN DE PUTTE LBA, VAN LFEUWEN MA, VAN DE PUTTE LBA,
VAN RIEI PLCM: Modified disease activity VAN RIEI PLCM: Modified disease activity
scores that include twenty-eight-joint counts. Development and validation in a prospective and longirudinal study of patients with rheumatoid arthritis. Arthritis Rhesm 1995; 38 : 44-8.
15. FRANSEN I, ANTONI C, MEASE PJ et al.: Performance of response criteria for assessing peripheral arthritis in patients with psoriatic athritis: analysis of data from randomized controlled trials of two tumour necrosis factor inhibitors. Ann Rheum Dis 2006; 65: 1373-8.

16. IWAHASHI M, YAMAMURA M, AITA T et al.: Expression of Toll-like receptor 2 on CD16+ blood monocytes and synovial tissue macrophages in meumatoid arthritis. Arthritis Rheum 2002; 46: 298-308.

17. ZHANG $X$, GLOGAIER M, ZHU F, KMM TH, CHIU B, NMAN RD: Innate immurity and arthritis: neutrophil Rac and Toll-like receptor 4 expression define outcomes in infectiontiggered arthritis. Arthritis Rhewm 2005; 52 : 1297-304.

18. YAVUZ S, ELBIR Y, TULUNAY A, EXSIOGLUDEMIRAIP E, DIRESKENELI H: Differential expression of toll-like receptor 6 on eram Cycinlocytes and monocytes implicates the role of microorgatusms in Behchet's disease etiopachogenesis. Rhewatol int 2008, 28: 401-6. 9. BAKFR BS, OVIGNE M, POWLES AV, CORCORAN S. FRY L: Normal keratinocytes express Tolllike receptors (TLRs) 1.2 and 5: modulation of TLR expression in chronic plaque psoniasis. Br J Dermatol 2003; 148: 670-9.

20. DE RYCKF L, VANDOOREN B, KRUTTHOF E, DE KEYSER F, VEYS EM, BAETEN D: Tumor necrosis factor $\alpha$ blockade treatment downmodulates the increased systemic and local expression of toll-like receptor 2 and toll-like receptor 4 in spondylarthropathy. Arthritis Rheum 2005; 52: 2146-58.

21. DE KFYSER F, EIFWAUT D, DE VOS M et al:: Bowel inflammation and the spondyloarthropathies. Rheum Dis Clin North Am 1998; 24: 785-813. 